\section{Check for updates}

Cite this: Inorg. Chem. Front., 2019, 6,3440

Received 31st July 2019,

Accepted 2nd October 2019

DOI: 10.1039/c9qi00965e

rsc.li/frontiers-inorganic

\title{
Chemically modified electrodes with MOFs for the determination of inorganic and organic analytes via voltammetric techniques: a critical review
}

\author{
Anastasia D. Pournara,$\uparrow^{\mathrm{a}}$ Georgios D. Tarlas,$\uparrow^{\mathrm{b}}$ Giannis S. Papaefstathiou (DD $\star^{\mathrm{b}}$ and \\ Manolis J. Manos iD *a
}

\begin{abstract}
Voltammetric analytical techniques combine exceptional sensitivity, low cost, portability and capability for simultaneous determination of multiple analytes. The sensitivity of voltammetric analysis is largely determined by the efficiency of the working electrode. Electrodes modified with metal organic frameworks (MOFs) seem particularly promising for use in the analysis of a series of important inorganic and organic analytes. Nevertheless, research on chemically modified electrodes with MOFs is still in its infancy. In this critical review, we present the current status of research related to MOF-modified electrodes highlighting the respective MOF-modified electrodes which are based on MOFs that show exceptional chemical stability or/and sorption capability towards the targeted analytes. We also provide perspectives for future research aiming at motivating additional scientists to be involved in this exciting field of MOF-based electroanalytical sensors.
\end{abstract}

\section{Introduction}

Metal organic frameworks (MOFs) are polymeric metal complexes with potential voids that have received much attention

${ }^{a}$ Laboratory of Inorganic Chemistry, Department of Chemistry,

University of Ioannina, 45110 Ioannina, Greece. E-mail: emanos@cc.uoi.gr

${ }^{b}$ Laboratory of Inorganic Chemistry, Department of Chemistry, National and

Kapodistrian University of Athens, Panepistimiopolis, 157 71, Zografou, Greece.

E-mail: gspapaef@chem.uoa.gr

$\dagger$ These authors contributed equally.

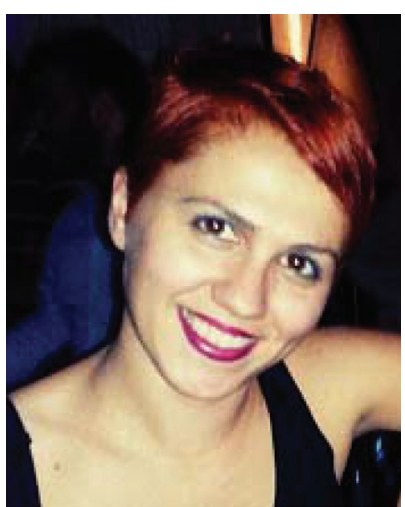

Anastasia D. Pournara
Anastasia Pournara received her degree in Biology (2008) and her Ph.D. (2014) in Inorganic Chemistry from the University of Ioannina, Greece, under the supervision of Prof. D. KovalaDemertzi. Since 2015, she has been a postdoctoral fellow in the group of Dr M. J. Manos at the University of Ioannina. Her research is focused on the synthesis of metal organic frameworks with interesting ionexchange properties towards organic dyes and heavy metals.

over the last two decades. Besides their rich chemistry, MOFs are attractive for their potential applications in various fields. ${ }^{1}$ MOFs are particularly appealing as sensors since they can combine highly porous structures with a variety of functional groups leading to the fast diffusion of analytes into their pores and enhanced framework-analyte interactions. So far, the majority of research is directed towards the development of MOF-based luminescent sensors. ${ }^{2}$ Such sensory materials have shown excellent detection properties for a series of inorganic and organic pollutants, as a result of substantial modification of the emission properties of MOFs in the presence of trace

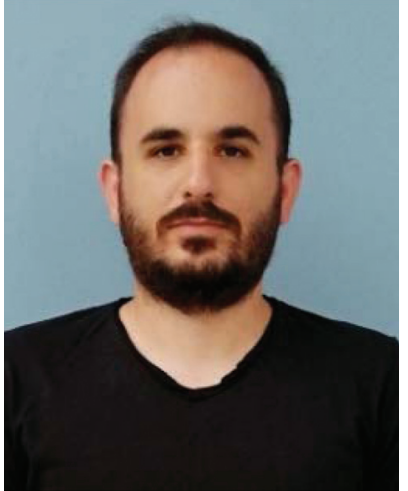

Georgios D. Tarlas
Georgios D. Tarlas received his degree in Chemistry (2012), his Masters in Inorganic Chemistry and Technology (2015) and his Ph.D. (2019) from the Department of Chemistry of the National and Kapodistrian University of Athens under the supervision of Prof. G. S. Papaefstathiou. His research is focused on the synthesis, characterization and postsynthetic modification of functionalized metal-organic frameworks with interesting sorption and electronic properties. 
amounts of specific analytes. A number of review articles discuss in detail the features of MOFs as luminescent sensors. ${ }^{3}$ Although luminescence-based sensing has several advantages (e.g. portability, low cost, and low detection limits), it also suffers from limitations such as limited selectivity and inability for simultaneous determination of multiple analytes. $^{2,3}$

More recently, MOFs have been utilized for the modification of electrodes to be used for the voltammetric determination of inorganic and organic species. As we will discuss in more detail below, chemically modified electrodes show enhanced accumulation of the analysed species, as a result of the high sorption capability of the modifier (e.g. MOF) towards the targeted analyte. ${ }^{4}$ Thus, voltammetric analysis using such modified electrodes offers a number of advantages such as exceptionally low detection limits, high selectivity and simultaneous determination of several analytes. ${ }^{4}$ Although MOFs that have been utilized so far in voltammetric determination show great promise, research in this field is still in its infancy. There are particular challenges to be addressed for the extended development of MOF-based electrodes. ${ }^{5}$ For example, up to now, there are several publications which describe the modification of electrodes with MOFs but in many cases there is limited information about the stability of the MOF in the working environment (e.g. they do not discuss if the MOFs are chemically stable in aqueous media). ${ }^{5}$ There is also limited information in many relevant publications about the selectivity and the sorption ability of MOFs towards specific analytes while the nature of the frameworks (pore size, charge of the frameworks, functional groups, etc.) does not always justify their choice as chemical modifiers for electrodes.

So far, this new field of MOF-based electroanalytical sensors has not been reviewed critically. Here we aim to present the current status of research on MOF-modified electrodes discussing selected examples and their applications related to voltammetric determination of important inorganic and organic analytes, highlighting those examples where unambiguous information on the chemical (and hydrolytic) stability of the MOFs ${ }^{6}$ or sorption studies have been reported. Prior to the presentation of examples of MOF-modified electrodes used in voltammetric analysis of inorganic and organic analytes, we discuss briefly the basic principles of voltammetric analytical techniques focusing on stripping voltammetry and provide a short introduction on chemically modified electrodes. ${ }^{4}$ We further suggest directions and perspectives for future research on the use of MOF-modified electrodes for analytical applications, focusing on the specific characteristics that MOFs should possess in order to be utilized as electrode modifiers for voltammetric determination. Our ambition is that the present review will inspire scientists with interest in MOFs to extend their research efforts towards this new field of MOF-based analytical applications.

\section{Background information on stripping voltammetry and chemically modified electrodes}

One of the most powerful voltammetric techniques is stripping voltammetry which combines particularly low detection limits, portability and capability for simultaneous determination of multiple analytes. ${ }^{4,7}$ Stripping voltammetry involves accumulation (pre-concentration) of the analyte on the working electrode followed by its release (stripping) to the solution. For example, stripping voltammetry analysis of metal ions $\left(\mathrm{M}^{n+}\right)$ includes deposition of $\mathbf{M}^{n+}$ on the working electrode with simultaneous reduction of $\mathrm{M}^{n+}$ to $\mathbf{M}^{0}$ (pre-concentration step) and a subsequent electrochemical stripping step of the accumulated analyte (oxidation of $\mathrm{M}^{0}$ to $\mathrm{M}^{n+}$ ) producing a peak current proportional to the analyte's concentration in solution (Fig. 1). The three most commonly used variations of stripping voltammetry are anodic (in this method, used for most metal ions, stripping is achieved by scanning anodically towards a

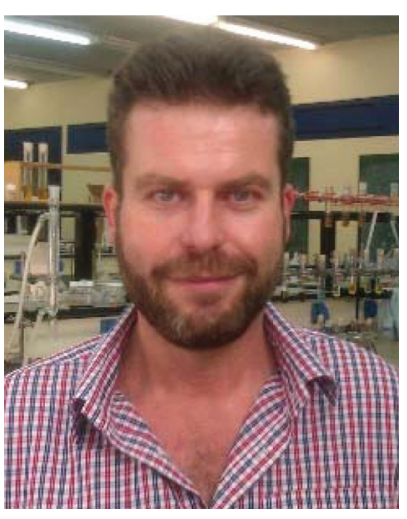

Giannis S. Papaefstathiou
Giannis S. Papaefstathiou received his Chemistry degree in 1998 and his Ph.D. in Inorganic Chemistry in 2002 from the University of Patras, Greece. After two years' postdoctoral work at the University of Iowa, he joined the Department of Chemistry of the National and Kapodistrian University of Athens in 2006 where he currently serves as an Associate Professor of Inorganic Chemistry. His research focuses on aspects of coordination chemistry and supramolecular chemistry.

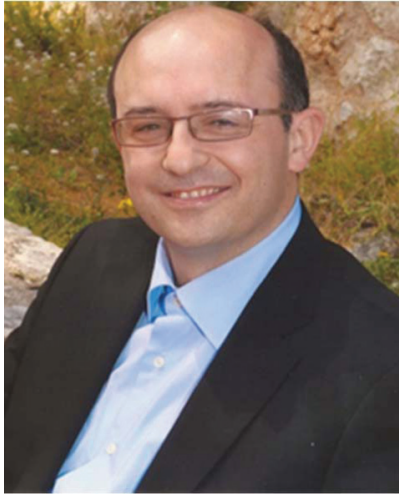

Manolis J. Manos
Dr Manolis J. Manos is an Associate Professor of Inorganic Chemistry at the University of Ioannina, Greece. He completed his Ph.D. at the same university under the supervision of Prof. T. Kabanos. He was a postdoctoral researcher in the group of Prof. M. Kanatzidis at MSU and $N U$ and in the group of Prof. A. Tasiopoulos at the University of Cyprus. His research interests are directed toward materials and composites with ion exchange and luminescence sensing properties. 

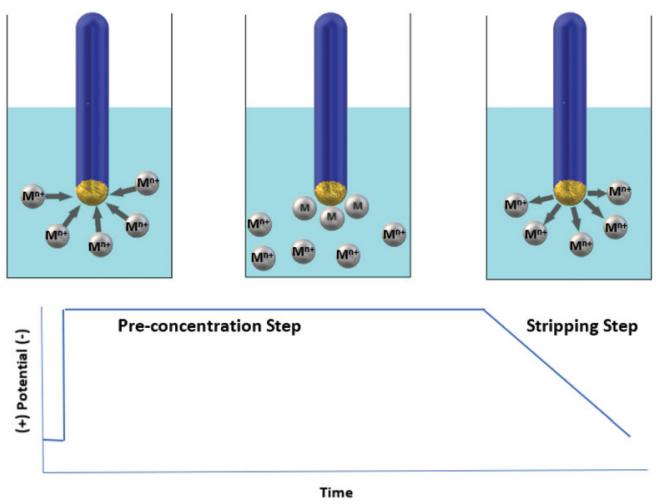

Fig. 1 Schematic representation of the determination method for heavy metals via stripping voltammetry.

more positive potential), cathodic (in this method, used for several inorganic anions, stripping is achieved by scanning cathodically towards a more negative potential) and adsorptive stripping voltammetry (in this method, which is used for some metal ions and organic molecules, deposition involves adsorption of a metal complex or organic analyte on the working electrode's surface without electrolysis of the adsorbed species). ${ }^{8}$ In addition, depending on the type of the potential waveform used in the stripping step (mainly differential pulse and square wave), the voltammetric analytical technique is called Differential Pulse Stripping Voltammetry (DPSV) or Square Wave Stripping Voltammetry (SWSV).

A prerequisite for sensitive electrochemical measurements, which can achieve detection limits even at ppt levels, is the appropriate selection of the working electrode material. Traditionally, stripping voltammetry makes use of the Hanging Mercury Drop Electrode (HMDE), where mercury forms an amalgam with a metal ion and the current is measured after an oxidation reaction. ${ }^{4}$ However, health considerations and environmental limitations have led to intense research efforts towards the replacement of the highly toxic mercury-based electrode with other types of environmentally friendly electrodes. To this end, electrodes modified with several materials have been developed and tested for the voltammetric determination of various analytes. For example, as an alternative to mercury-based electrodes, carbon paste electrodes (CPEs) constitute a special class of heterogeneous carbon electrodes consisting of a mixture of conductive graphite powder and a suitable chemical modifier. ${ }^{9}$ The material that is chosen to serve as a chemical modifier in an electrode should at least have the following characteristics: (i) stability under the experimental conditions, (ii) stability after multiple pre-concentration-stripping cycles and (iii) high selectivity and sorption capacity for the targeted analyte. The latter is particularly important as it is directly related to the pre-concentration step (deposition of the analyte on the electrode) and therefore greatly influences the observed detection limits. Several already reported electrode modifiers include nanomaterials/ionophores, ${ }^{10}$ bismuth modified zeolite, ${ }^{11}$ antimony powder, ${ }^{12}$ multi-walled carbon nano- tubes, ${ }^{13}$ double-stranded DNA and ferric oxide nanoparticles, ${ }^{14}$ $\mathrm{Ca}_{10}\left(\mathrm{PO}_{4}\right)_{6}(\mathrm{OH})_{2}{ }^{15}$ tripolyphosphate-modified kaolinite clay, ${ }^{16}$ a mixture of titanium dioxide/zirconium dioxide, ${ }^{17}$ graphene, ${ }^{18}$ and other polymeric materials. ${ }^{19}$ Although there is a plethora of chemical modifiers reported in the literature, the search for new materials that would lead to enhanced analytical performance towards the targeted analytes is continuous.

MOFs seem to have high potential to be used for the modification of electrodes for voltammetric analyses. Indeed, they could be superior over other materials which are currently being tested for this purpose. The surface areas of MOFs can reach values as high as $7000-8000 \mathrm{~m}^{2} \mathrm{~g}^{-1}$, higher than those commonly found for other types of porous materials. ${ }^{20}$ Thus, various analytes can rapidly diffuse into the pores of certain highly porous MOFs thereby enhancing pre-concentration. In addition, MOFs can be derivatized with a variety of functional groups, something that is either very difficult or even impossible with conventional materials. By choosing appropriate functional groups, MOFs can display selective sorption of analytes in the presence of various competitive species, a fact that is also highly beneficial for the pre-concentration of analytes in the course of voltammetric analysis.

\section{Determination of organic analytes with MOF-modified electrodes}

\subsection{General comments}

In recent years, there has been a large number of literature reports describing the fabrication and utilization of MOFbased modified electrodes for the detection of organic molecules. The driving force behind these efforts is identified as the need for the detection and quantification of organic molecules that: (i) demonstrate biological action crucial to maintaining human health such as glucose, ${ }^{21}$ (ii) act as explosives such as 2,4,6-trinitrophenol ${ }^{22}$ and (iii) exist as traces in food, such as methyl parathion, ${ }^{23}$ which is one of the most widely used pesticides in agricultural practices in order to control a wide range of pests infesting various crops.

It is apparent that MOFs which are either soluble or degradable in aqueous media (the most common working environment for an electrode) or lose their crystallinity and therefore their ordering and porosity, the main feature that classifies a coordination polymer as a MOF, are inappropriate to be used as electrode modifiers. Nevertheless, modified electrodes,


MOF-5 ( $\left[\mathrm{Zn}_{4} \mathrm{O}(\mathrm{BDC})_{3}\right], \mathrm{H}_{2} \mathrm{BDC}=$ terephthalic acid $)$, which are among the best defined and most studied MOFs, have been used for the determination of organic molecules, despite the fact that the aforementioned materials are not stable in aqueous media. ${ }^{24,25}$ Recently, Li et al. ${ }^{22}$ and F.A. Sofi et al. ${ }^{26}$ described the development of a glassy carbon electrode modified with HKUST-1 as a sensitive electrochemical sensor for the determination of dopamine, an important neurotransmitter in the mammalian central nervous system, using Differential Pulse Voltammetry (DPV). They managed to detect 
the targeted analyte in a wide range of concentrations ranging between $5.0 \times 10^{-7}-1.0 \times 10^{-4} \mathrm{M}$ and $12.5 \times 10^{-6}-175 \times 10^{-6} \mathrm{M}$, respectively, with an estimated detection limit of $1.5 \times 10^{-7} \mathrm{M}$ and $0.11 \times 10^{-9} \mathrm{M}$, respectively. In addition, HKUST- 1 and its analogues have been extensively utilized for the modification of electrodes, claiming selective and sensitive detection, with low detection limits, excellent stability and reproducibility for molecules such as 2,4,6-trinitrophenol, ${ }^{27}$ catechol, $^{28-30}$ hydroquinone, ${ }^{28,29}$ 2,4-dichlorophenol, ${ }^{30 b}$ glyphosate, ${ }^{31}$ resorcinol $^{29}$ bisphenol $\mathrm{A},{ }^{32,33}$ paracetamol, ${ }^{25,34,35}$ caffeine, ${ }^{34}$ glucose, ${ }^{36}{ }_{\text {L-cysteine }}{ }^{37}$ and methyl parathion. ${ }^{38}$ On the other hand, Li et al. ${ }^{39}$ demonstrated a new electrochemical sensor which was constructed by the in situ assembly of MOF-5 onto a PGN nanocomposite, for the determination of echinacoside, one of the natural ingredients extracted from the herb cistanche, with a limit of detection of $1.0 \times 10^{-8} \mathrm{M}$.

\subsection{Examples of chemically stable MOFs used as electrode modifiers for the determination of organic analytes}

Despite the above, there are also several examples of chemically stable MOFs that have been utilized as modifiers for electrodes. As we will see in the following discussion, such MOFs have improved significantly the analytical performance of the electrodes, presumably due to their high surface area and their potential capability for rapid sorption of organic analytes into their pores. These MOFs are summarized in Table 1 and analyzed hereafter. Nevertheless, the published studies on MOFmodified electrodes for determination of organic analytes did not include sorption studies for the examined organic molecules.

A family of MOFs with remarkable and ultrahigh chemical stability under aqueous conditions constitute the $\mathrm{Zr}_{6}$ based MOFs. ${ }^{40}$ Recently, N. Karimian, H. Bagheri et al. ${ }^{41}$ described the fabrication of a glassy carbon electrode (GCE) modified with a composite consisting of $\mathrm{TiO}_{2}$ functionalized graphene oxide (TGO) and UiO-66 $\left[\mathrm{Zr}_{6} \mathrm{O}_{4}(\mathrm{OH})_{4}(\mathrm{BDC})_{6}\right]$, for the simultaneous detection of paraoxon (POX) and chlorpyrifos (CPF). The latter are used as pesticides and insecticides, respectively, and are considered hazardous to human health. The UiO-66 MOF consists of hexanuclear clusters that serve as 12-coordinated (12-c) nodes extended in space through the phenyl rings of the ligands, creating a 3D framework with channels $\sim 6 \AA$ in diameter. The composite (TGO@UiO-66) was synthesized by a similar method to that for the synthesis of UiO-66. The procedure includes the dispersion of TGO in DMF by sonication, followed by the addition of UiO-66's components in DMF solution. The resulting suspension was further sonicated and transferred into an autoclave at $120{ }^{\circ} \mathrm{C}$ for $12 \mathrm{~h}$. The preparation of the TGO@UiO-66/GCE was achieved by dropping $6.0 \mu \mathrm{L}$ of a suspension of TGO@UiO-66 in ethanol onto a bare GCE surface followed by air-drying. The phase purity of the prepared materials was investigated by X-ray diffraction analysis. The observed diffraction peaks of UiO-66 were in good agreement with those of the pristine material, while the Powder X-ray Diffraction (PXRD) pattern of TGO@UiO-66 indicated that the presence of TGO did not prevent the formation of UiO-66. $\mathrm{N}_{2}$ adsorption-desorption measurements confirmed the porosity of both UiO-66 and the TGO@UiO-66 composite. The modified TGO@UiO-66/GCE electrode was tested for the determination of POX and CPF separately and simultaneously (Fig. 2), using Square Wave Voltammetry (SWV). In the case of POX, the SWV curves were recorded at various concentrations ranging between $1.0 \times 10^{-9}$ and $100 \times 10^{-9} \mathrm{M}$ and in the presence of $50 \times 10^{-9} \mathrm{M} \mathrm{CPF}$. The current peaks on SWV curves of POX indicated that the existence of $50 \times 10^{-9} \mathrm{M}$ CPF had no effect on the determination of POX. CPF determination within the $5-300 \times 10^{-9} \mathrm{M}$ range was achieved following the same route. The detection limits for the POX and CPF were estimated to be $0.2 \times 10^{-9} \mathrm{M}$ and $0.1 \times 10^{-9}$ $\mathrm{M}$, respectively. The optimized performance of the electrochemical assay was attributed to the high surface area and excellent conductivity of the TGO@UiO-66 composite which facilitated the electron transfer between the analyte and the electrode surface.

M. Deng, L. Guo et al. ${ }^{42}$, using the same MOF (UiO-66), synthesized under hydrothermal conditions a composite, combin-

Table 1 The detection limits and linear response ranges of MOF-modified glassy carbon electrodes stable in the working environment using the corresponding organic analytes and detection methods








Fig. 2 Schematic representation of the procedure for the determination of POX and CPF by the TGO@UiO-66/GCE modified electrode. Reproduced from ref. 41 with permission from the Royal Society of Chemistry.

ing UiO-66 with mesoporous carbon (MC). The UiO-66/MC composite was characterized by a plethora of techniques such as SEM, TEM, PXRD and $\mathrm{N}_{2}$ adsorption-desorption isotherms, which proved the stability and the porous nature of the composite. The preparation of the modified electrode was achieved by the dispersion of $5 \mu \mathrm{L}$ of a DMF suspension of the UiO-66/ MC composite on the mirror like surface of a GCE. The UiO-66 based electrode was utilized for the determination of several di-hydroxybenzene molecules such as hydroquinone (HQ), catechol (CT) and resorcinol (RS) which have been categorized as emerging contaminants in aqueous media. Quantitative determination was performed using DPV. Under optimized conditions, the electrochemical sensor showed a wide linear response for each targeted analyte, that is, $0.5-100 \times 10^{-6} \mathrm{M}$, $0.4-100 \times 10^{-6} \mathrm{M}$ and $30-400 \times 10^{-6} \mathrm{M}$ for HQ, CT and RS, respectively, with the limit of detection reaching the values of $0.056 \times 10^{-6}, 0.072 \times 10^{-6}$ and $3.51 \times 10^{-6} \mathrm{M}$, respectively. The outstanding electrochemical performance of the modified electrode for the simultaneous determination of the di-hydroxybenzene isomers was attributed to the UiO-66/MC composite, which showed excellent electrochemical stability, larger pore size and good conductivity that enabled faster electron transfer and contributed to mass transfer.

The amino-functionalized derivative of UiO-66 (UiO-66- $\mathrm{NH}_{2}$ $\left[\mathrm{Zr}_{6} \mathrm{O}_{4}(\mathrm{OH})_{4}\left(\mathrm{NH}_{2}-\mathrm{BDC}\right)_{6}\right], \mathrm{NH}_{2}-\mathrm{BDCH}_{2}=$ 2-aminoterephthalic acid) has emerged as a sorbent for heavy metal-ions such as $\mathrm{Cd}^{2+}$ and $\mathrm{Pb}^{2+}$ (the maximum sorption capacity was found 268 and $293 \mathrm{mg} \mathrm{g}^{-1}$ for $\mathrm{Cd}^{2+}$ and $\mathrm{Pb}^{2+}$, respectively). ${ }^{43 a}$ Due to the excellent adsorption ability, which is attributed to the $-\mathrm{NH}_{2}$ groups, materials such as UiO-66- $\mathrm{NH}_{2}$ are suitable for the construction of biosensors because they act as ideal signal carriers. ${ }^{43}$ There will be no further discussion on this class of electrochemical bio-sensors that incorporate $\mathrm{MOFs}^{44}$ because it is out of the scope of this review.

T.-Y. Huang, C.-W. Wu et $a l^{45}$ demonstrated a dopamine sensor, composed of poly(3,4-ethylenedioxythiophene) nanotubes (PEDOT NTs) coated with MOF-525 $\quad\left[\mathrm{Zr}_{6} \mathrm{O}_{4}(\mathrm{OH})_{4}\right.$ $\left.\left(\mathrm{TCPP}-\mathrm{H}_{2}\right)_{3}\right] \quad\left(\mathrm{H}_{4}\right.$ TCPP- $\mathrm{H}_{2}=$ tetrakis(4-carboxyphenyl)porphyrin). MOF-525 is a porphyrin-containing MOF that is excep- tionally chemically stable, maintaining its structure upon its treatment with water and various organic solvents and can be metalated with iron(III) and copper(II) to yield its metalated analogues without losing its high surface area and chemical stability. ${ }^{46}$ MOF-525 was synthesized from the reaction of zirconyl chloride with $\mathrm{H}_{4}$ TCPP- $\mathrm{H}_{2}$ in a DMF solution at $65{ }^{\circ} \mathrm{C}$ for 3 days. The $\mathrm{Zr}_{6}$ clusters serve as 12-c nodes and the ligand as a 4-c node resulting in an ftw network. MOF-525 acted as an electrocatalytic surface, while PEDOT NTs acted as charge collectors that rapidly transported the electrons from the MOF-525 surface. The response of the electrode was measured by DPV with the linear concentration range of dopamine detection estimated at $2-270 \times 10^{-6} \mathrm{M}$ and the detection limit reaching the value of $0.04 \times 10^{-6} \mathrm{M}$. The enhanced electrochemical performance was attributed to the synergistic effects originating from the simultaneous presence of MOF-525 nanocrystals, which function as electrode materials with numerous electrochemically active sites and the PEDOT NTs, which serve as charge collectors to efficiently transport electrons to the electrode.

MOF-525 was also combined, by M. Cao, L. Guo et al., ${ }^{47}$ with a macroporous carbon (MPC), and the resulting MOF-525/MPC composite was successfully prepared by a solvothermal reaction and used for the determination of luteolin, which is a common flavonoid with neuroprotective and antioxidant effects, by DPV. According to the DPV curves, the luteolin sensor (MOF-525/MPC-2/GCE) showed two parts of linearity in the ranges of $0.005-0.1 \times 10^{-6}$ and $0.1-5 \times 10^{-6} \mathrm{M}$ with a limit of detection of $0.35 \times 10^{-9} \mathrm{M}$. The electrochemical performance was attributed to the large pore size, high BET surface area and good conductivity of the MOF-525/MPC composite, which can conduce mass transfer and quicken electron transfer.

H. Wang, F. Lu et al., ${ }^{48}$ in order to overcome certain drawbacks associated with the majority of MOFs, such as the low electrical conductivity and poor chemical stability, combined MIL-101-Cr $\left[\mathrm{Cr}_{3} \mathrm{O}(\mathrm{F} / \mathrm{OH})\left(\mathrm{H}_{2} \mathrm{O}\right)_{2}(\mathrm{BDC})_{3}\right]$ with reduced graphene oxide (rGO), which is one of the most promising electroconductive materials. The resulting composite material was used as a chemical modifier in a carbon paste electrode (CPE) for the quantitative determination of CT and HQ. MIL-101-Cr is a mesoporous MOF (based on super-tetrahedral units, each one consisting of three chromium trimers that are bridged by the $\mathrm{BDC}^{2-}$ linkers) and shows incredible stability (including stability against hydrolysis). MIL-101-Cr contains two types of cages with diameters of 34 and $29 \AA$. The corresponding cage windows are 16 and $12 \AA$ in size and they are diffusion paths for adsorbates. The authors hypothesized that the incorporation of rGO in MIL-101-Cr crystals could enhance their conductivity and electron transfer and thus allow better performance in electrochemical sensing systems. The synthesis of the MIL-101-Cr/rGO composite included the dispersion of graphene oxide and terephthalic acid followed by the addition of a solution of tetramethylammonium hydroxide. Then, $\mathrm{Cr}$ $\left(\mathrm{NO}_{3}\right)_{3} \cdot 9 \mathrm{H}_{2} \mathrm{O}$ was added under vigorous stirring and transferred into an autoclave that was heated for $24 \mathrm{~h}$ at $150{ }^{\circ} \mathrm{C}$. 
The obtained composites were denoted as MIL-101-Cr-rGO-1, MIL-101-Cr-rGO-2 and MIL-101-Cr-rGO-3, according to the amount of graphene oxide that was used (i.e. $1 \mathrm{wt} \%, 2 \mathrm{wt} \%$ and $5 \mathrm{wt} \%$, respectively). The fabrication of the CPE included the grounding of the composite with graphite powder with a weight ratio of $14: 1$, followed by mixing with paraffin. Finally, a copper wire was inserted within the body of the electrode as inner electrical contact. The modified electrode after the characterization of the composites by IR, XRD, SEM and EIS was tested by recording cyclic voltammograms of HQ and CT (simultaneously) in phosphate saline solution, giving a broad oxidation peak, with the MIL-101-Cr-rGO modified electrode exhibiting the ability to identify the two isomers by increasing the oxidation and reduction peak currents by raising the rGO content in the electrode. The DPV results indicated that the oxidation peak shifted negatively with the increase of the $\mathrm{pH}$ value, due to the participation of $\mathrm{H}^{+}$in the electrode reaction, with the quantitative detection of $\mathrm{HQ}$ and $\mathrm{CT}$ taking place in phosphate-buffered solution (PBS) with $\mathrm{pH}=7.5$. The determination of HQ and CT was performed in a single analyte solution, with the regression equation showing linearity in two ranges (HQ: $4-100 \times 10^{-6}$ and $100-1000 \times 10^{-6} \mathrm{M}$, CT: $10-60 \times$ $10^{-6}$ and $\left.60-1400 \times 10^{-6} \mathrm{M}\right)$. The detection limits were estimated at $0.66 \times 10^{-6} \mathrm{M}$ and $4.1 \times 10^{-6} \mathrm{M}$ for HQ and CT, respectively.

Another MIL-101-Cr/rGO composite electrochemical sensor, was developed by J. Gu, L. Guo et al., ${ }^{49}$ for the detection of metronidazole, an oral drug that pertains to a class of nitroimidazole derivatives and is crucial for the treatment of anaerobic bacterial and protozoal diseases. They followed a similar pathway (to the previous MIL-101-Cr-rGO composite) for the MIL-101-Cr/rGO composite synthesis and were confronted with the same challenges, with the metronidazole detection achieved at an optimal operation $\mathrm{pH}$ value of 7.5 in the concentration ranges of $0.5-200 \times 10^{-6} \mathrm{M}$ and $200-900 \times 10^{-6}$ M. The detection limit was estimated at $0.24 \times 10^{-6} \mathrm{M}$. Again, the electrocatalytic ability of the MIL-101-Cr/rGO composite was attributed to the synergistic effect of the super electrical conductivity of rGO and the distinctive structural features of MIL-101-Cr.

The combination of MIL-101-Cr with $\mathrm{MoS}_{2}$ forms an MIL-101-Cr/ $\mathrm{MoS}_{2}$ composite, which involves the $\mathrm{Cr}$ (III) MOF and exemplifies a synergetic advantage. W. Zhang, Y. Zhang et $a l .{ }^{50}$ introduced the molecular imprinting technique (MIT) to design and synthesize molecularly imprinted polymers (MIP), which can effectively promote the selectivity of the MIL-101-Cr/ $/ \mathrm{MoS}_{2} / \mathrm{GCE}$ towards quercetin (Qu), a member of the family of flavonoids with antioxidant activity. The MIL-101$\mathrm{Cr} / \mathrm{MoS}_{2} / \mathrm{GCE}$ was constructed by dropping $10 \mu \mathrm{L}$ of a suspension consisting of $10 \mathrm{mg}$ of MIL-101-Cr and $\mathrm{MoS}_{2}$ (in a 1:6 molar ratio) onto the surface of a pre-treated GCE electrode. To further stabilize the electrode, $10 \mu \mathrm{L}$ of a 1 wt $\%$ Nafion solution was used. The aforementioned sensor was polymerized at $0.7 \mathrm{~V}$ for $100 \mathrm{~s}$, using chronocoulometry when inserted into the polymerization solution (pyrrole in $0.1 \mathrm{M}$ $\left.\mathrm{H}_{2} \mathrm{SO}_{4} / 0.01 \mathrm{M} \mathrm{Qu}\right)$. The electrochemical behavior of the MIP/
MIL-101-Cr/ $\mathrm{MoS}_{2} / \mathrm{GCE}$ was investigated by DPV under different concentrations of Qu with the current peak increasing with the increase of the concentration of quercetin. The current-concentration of $\mathrm{Qu}$ ratio exhibited a linear relationship in two ranges, which were $0.1-10.5 \times 10^{-6} \mathrm{M}$ and $10.5-700 \times 10^{-6}$ M. The detection limit of the sensor was estimated at $0.06 \times$ $10^{-6} \mathrm{M}$ in $\mathrm{PBS}$ and $\mathrm{pH}=3.5$. The results indicated that the MIL-101-Cr/MoS 2 composite as an electrode modifier exhibited the advantages of the large surface area of MIL-101-Cr and the electrocatalytic performance of $\mathrm{MoS}_{2}$. Furthermore, the combination of MIL-101-Cr and $\mathrm{MoS}_{2}$ created a chemically catalytic environment on the electrode surface, which allowed specific interactions between $\mathrm{Qu}$ and the organic parts of MIL-101-Cr.

L. Wang, Y. Zhang et al. ${ }^{51}$ took advantage of the incredible chemical stability of the zeolitic imidazolate framework ZIF-8 $\left(\left[\mathrm{Zn}(\mathrm{MeIM})_{2}\right], \mathrm{H} \text {-MeIM }=2 \text {-methylimidazolate }\right)^{52}$ to decorate leaf-like ZIF-8 (ZIF-L) with Au nanoparticles, in order to modify a GCE for the effective determination of Acetaminophen, the most common over-the-counter antipyretic and analgesic drug. ZIF-8 is a MOF with a sod topology, exhibiting a nanopore structure formed by four-ring and six-ring $\mathrm{ZnN}_{4}$ moieties. The typical preparation procedure includes the addition of solid $\mathrm{Zn}\left(\mathrm{NO}_{3}\right)_{2} \cdot 4 \mathrm{H}_{2} \mathrm{O}$ and $\mathrm{H}-\mathrm{MeIM}$ in a glass vial containing DMF and keeping the reaction mixture at $140{ }^{\circ} \mathrm{C}$ for $24 \mathrm{~h}$. The preparation of the $\mathrm{Au}$ nanoparticles and the Au/ZIF-L composite was achieved following previously published methods with a minor modification in the case of ZIF-L. ${ }^{53,54}$ The synthesis of the GCE's additives was followed by the extensive characterization of both ZIF-L and Au/ZIF-L. The size of the Au nanoparticles was estimated at $13.62 \mathrm{~nm}$, while the porosity of ZIF-L and $\mathrm{Au} / \mathrm{ZIF}-\mathrm{L}$ was confirmed by BET measurements, which revealed the microporous nature of the materials. The electrode was tested by electrochemical impedance spectroscopy (EIS) to confirm that the modification had taken place and then its behavior as an electrocatalyst and sensor for Acetaminophen, using cyclic voltammetry (CV) and DPV, respectively, was studied. The results of Acetaminophen determination by DPV revealed two linear segments. The linear concentration segments were found in the ranges of $0.056-0.56 \times 10^{-6} \mathrm{M}$ and $3.50 \times 10^{-6}$ to $0.056 \times 10^{-3} \mathrm{M}$, with a limit of detection of $1.02 \times 10^{-6} \mathrm{M}$. The long-term stability of the sensor, a key parameter for the development and application of sensors in electrochemistry, was confirmed by placing the Au/ZIF-L/GCE at $4{ }^{\circ} \mathrm{C}$ for two weeks. The stored sensor was tested again by DPV in the presence of $0.05 \times 10^{-3} \mathrm{M}$ of Acetaminophen, showing the same results. The electrode performance was attributed to the synergistic effect of the unique structures of ZIF-L with a leaf-like morphology and the strong electrocatalytic activity of $\mathrm{Au}$ NPs for small molecules. The combination of large specific surface area and porosity made ZIF-L a platform for loading the Au NPs. Thus, the Au/ZIF-L nanohybrids offered a favorable microenvironment for transferring species in solution, and were beneficial for accelerating electron transfer between the electrode and the species in solution. 
In order to construct a sensitive electrochemical sensor for the detection of 2,4,6-trichlorophenol (2,4,6-TCP), which is commonly used in industry and agricultural chemicals, T. Zhang, J. Wang et al. ${ }^{55}$ developed an electrochemical sensor by immobilizing hemin into Cu-MOF-74 ([ $\left.\mathrm{Cu}_{2}(\mathrm{DHTP})\right]$, $\mathrm{H}_{4}$ DHTP $=$ 2,5-dihydroxyterephthalic acid). Cu-MOF-74 was synthesized by adding $\mathrm{H}_{4}$ DHTP and $\mathrm{Cu}\left(\mathrm{NO}_{3}\right)_{2} \cdot 3 \mathrm{H}_{2} \mathrm{O}$ in a vial containing $20 \mathrm{~mL} \mathrm{DMF}$ and $1 \mathrm{~mL}$ 2-propanol which was heated at $80{ }^{\circ} \mathrm{C}$ for $18 \mathrm{~h}$. From the topological point of view MOF-74 is a 3D MOF with rod Secondary Building Units (SBUs) that is based on edge sharing polyhedra bridged to the other two dimensions by the phenyl rings of the ligand. This classifies MOF-74 as an $\mathrm{I}^{1} \mathrm{O}^{2}$ framework. ${ }^{56}$ The preparation of hemin/Cu-MOF-74 was achieved by the addition of $5 \mathrm{mg}$ of $\mathrm{Cu}-$ MOF-74 into $20 \mathrm{ml}$ of hemin solution $(2.2 \mathrm{~g}$ hemin in $10 \mathrm{ml}$ water and $15 \mathrm{ml} \mathrm{MeOH}$ ) which was then stirred for $6 \mathrm{~h}$. The hemin/Cu-MOF-74/GCE was prepared by coating the surface of a polished GCE (pre-treated with ethanol and double deionized water) with $5 \mu \mathrm{L}$ of a DMF homogeneous solution of hemin/Cu-MOF-74. The modification of the electrode was completed by further coating of the surface of the hemin/CuMOF-74/GCE with $5 \mathrm{~mL}$ of $0.5 \%$ Nafion solution. The fully modified electrode, before use, was stored at $4{ }^{\circ} \mathrm{C}$. The electrochemical behavior of the 2,4,6-trichlorophenol-hemin/CuMOF-74/GCE was investigated by recording cyclic voltammograms in $0.1 \mathrm{M}$ PBS solution $(\mathrm{pH}=7.0)$, which indicated the irreversible oxidation of the 2,4,6-trichlorophenol and the improved performance of the fully modified electrode against the MOF (only)-functionalized and bare electrodes. The quantitative detection of the 2,4,6-TCP was performed by DPV. The peak current increased linearly with the increase of the concentration of 2,4,6-trichlorophenol in the range of $0.01-9 \times$ $10^{-6} \mathrm{M}$. In this range, two linear ranges were revealed $\left(0.01-1.0 \times 10^{-6} \mathrm{M}\right.$ and 1.0-9.0 $\left.\times 10^{-6} \mathrm{M}\right)$ while the limit of detection was found at $0.005 \times 10^{-6} \mathrm{M}$. When hemin was immobilized in Cu-MOF-74, the current intensity at the hemin/Cu-MOF-74/GCE was higher than those at other composites, probably owing to the synergistic effect produced by hemin and $\mathrm{Cu}-\mathrm{MOF}-74$. The reason for the improved performance may be the contribution from the following properties: (i) Cu-MOF-74 consists of metal ions and organic ligands, which can adsorb more 2,4,6-TCP onto the electrode surface through $\pi-\pi$ stacking interactions. (ii) Cu-MOF-74 possesses high surface areas, favoring high hemin loading. (iii) The possible interaction between hemin and metal ions in Cu-MOF-74 increased the catalytic activity of hemin.

The combination of the trivalent lanthanide ion $\mathrm{Ce}^{3+}$ with trimesic acid $\left(\mathrm{H}_{3} \mathrm{BTC}\right)$ afforded the $1 \mathrm{D}$ coordination polymer, namely $\left[\mathrm{Ce}(\mathrm{BTC})\left(\mathrm{H}_{2} \mathrm{O}\right)_{6}\right]$ (Ce-MOF), which extends to the second dimension through $\pi-\pi$ interactions between the phenyl rings of the ligand. ${ }^{57} \mathrm{~J}$. Zhang et al. ${ }^{58}$ prepared a modified electrode by combining the Ce-MOF with the cationic surfactant cetyltrimethylammonium bromide (CTAB) via electrostatic interactions, in their effort to fabricate an ultrasensitive electrochemical bisphenol A (BPA) sensor. BPA is an organic monomer which is employed in the production of food packa- ging and is found in the environment, food and bodies of living organisms. The preparation of the CTAB/Ce-MOF composite was achieved when an aqueous solution of Ce-MOF $\left(1.0 \mathrm{~mL}, 2.0 \mathrm{mg} \mathrm{mL}{ }^{-1}\right)$ was added into $1.0 \mathrm{~mL}$ of $3.0 \mathrm{mg} \mathrm{mL}^{-1}$ CTAB. Before the modification, a bare GCE (3 $\mathrm{mm}$ diameter) was polished using 0.3 and $0.05 \mu \mathrm{m}$ alumina slurry and rinsed thoroughly with distilled water. The GCE was successively sonicated in a nitric acid/acetone mixture $(1: 1 \mathrm{v} / \mathrm{v})$ and distilled water, and afterwards the GCE was rinsed with distilled water and dried at room temperature. $4.0 \mu \mathrm{L}$ of the CTAB/Ce-MOF suspension was dropped onto the pretreated GCE. After drying at room temperature, the CTAB/Ce-MOF modified GCE (CTAB/ Ce-MOF/GCE) was successfully prepared. The PXRD measurements indicated that the nature of the as-synthesized Ce-MOF and the MOF that exist in the CTAB/Ce-MOF composite is unchanged which is evidence that the Ce-MOF is stable in aqueous media and that the electrode could be characterized as being successfully MOF-modified. The analytical performance of the modified electrode was studied by DPV. According to the DPV, the peak current gradually increased with the increase of BPA's concentration. The linear concentration range of $\mathrm{BPA}$ at $\mathrm{CTAB} / \mathrm{Ce}-\mathrm{MOF} / \mathrm{GCE}$ was found to be between $0.005 \times 10^{-6}$ and $50 \times 10^{-6} \mathrm{M}$ with the detection limit at $2.0 \times$ $10^{-9} \mathrm{M}$. In this work, the $\mathrm{CTAB} / \mathrm{Ce}-\mathrm{MOF}$ was prepared by the modification of self-assembled CTAB monolayers on the surface of the Ce-MOF via electrostatic interactions with the assistance of ultrasonication. The CTAB/Ce-MOF/GCE showed improved electrochemical response because of the enhanced preconcentration of BPA of the long alkane chain in CTAB via hydrophobic interactions.

Z. Chang, Y. Li et al. ${ }^{59}$ prepared by a one-step procedure a ferrocene-immobilized MOF-modified graphite electrode for the detection of Acetaminophen. They combined the ability of ferrocene to oxidize Acetaminophen with the ability of the zeolitic type $\left[\mathrm{In}_{48}(\mathrm{HImDC})_{96}\right]^{48-}\left(\mathrm{H}_{3} \mathrm{ImDC}\right.$ : 4,5-imidazoledicarboxylic acid) rho-ZMOF to host cationic species in its cavities due to its anionic nature. The synthesis and structure of the rho-ZMOF were first reported by Eddaoudi et al. and it was found to be chemically stable in aqueous media. ${ }^{60,61}$ It is based on 8-coordinated $\mathrm{In}^{3+}$ ions chelated by four HImDC ${ }^{2-}$ ligands. The ferrocene functionalized MOF was prepared in the presence of ferrocene in a reaction mixture similar to the one resulting in the original rho-ZMOF. The preparation of the electrode was achieved by the immersion of a graphite electrode in the aforementioned mixture in a glass bottle, which was then sealed and placed in an oven at $100{ }^{\circ} \mathrm{C}$ for $36 \mathrm{~h}$. The detection ability of the modified electrode was tested by DPV in an Acetaminophen solution with the concentration in the range of $1.0 \times 10^{-8}$ to $2.0 \times 10^{-5} \mathrm{M}$. The peak current increased gradually with the increase of the concentration of Acetaminophen and demonstrated good linearity in the abovementioned range with the detection limit estimated at $6.4 \times$ $10^{-9} \mathrm{M}$. In this work, an electrode was modified with a MOF in which ferrocene was immobilized, thus overcoming the problems caused by the increased solubility of ferrocene in its oxidized form. 


\section{Determination of inorganic analytes with MOF-modified electrodes}

\subsection{General comments}

Intense efforts have been made towards the development of analytical methods for determination of trace amounts of inorganic analytes, particularly heavy metals such as $\mathrm{Hg}^{2+}, \mathrm{Pb}^{2+}$, $\mathrm{Cd}^{2+}, \mathrm{Cu}^{2+}$ etc. Heavy metals are highly toxic, having even lethal effects as they are easily accumulated in humans and other living organisms. Therefore, their accurate, fast and reliable analytical determination in aqueous media is of vital importance. Stripping voltammetry is highly efficient for the quantitative analysis of heavy metals at extremely low concentrations, even at ppt levels. ${ }^{4}$ Nevertheless, the use of HDME in this analytical method causes concerns due to the high toxicity of mercury. Therefore, there has been interest in developing MOF-modified electrodes that could be as efficient as HDME for the determination of heavy metals without having the toxicity issues of mercury-based electrodes. In the following section, we discuss selected examples of MOFs that have been successfully utilized as modifiers in electrodes for voltammetric analysis of heavy metals. We focus on MOFs (summarized in Table 2) that were demonstrated to be efficient sorbents for heavy metals or combine hydrolytic stability and appropriate structural characteristics that could potentially facilitate the sorption of heavy metal ions by these materials.

\subsection{Single analyte determination}

i. Pb sensing studies. One of the most widely studied MOFs, namely MIL-101-Cr (Fig. 3), was investigated for the detection of trace levels of $\mathrm{Pb}^{2+} \cdot{ }^{62}$ As mentioned above, this material is highly stable and even maintains its BET surface area and PXRD pattern after immersion in boiling water for 1 week. $^{63,64}$ The detection of lead ions was carried out with differential pulse anodic stripping voltammetry (DPASV) using the MIL-101(Cr)/GCE modified electrode. The mechanism of



Fig. 3 Schematic representation of the fabrication of the MIL-101-Cr modified electrode and the accumulation of $\mathrm{Pb}^{2+}$ ions on its surface for the voltammetric determination of lead ions. Reproduced from ref. 62 with permission from the Royal Society of Chemistry.

this detection, suggested by the authors, first involves the accumulation of $\mathrm{Pb}^{2+}$ on the surface of the MIL-101(Cr)/GCE. Secondly, a constant voltage of $-1.1 \mathrm{~V}$ is applied resulting in the reduction of the complexed ions. Finally, $\mathrm{Pb}^{0}$ is stripped back as $\mathrm{Pb}^{2+}$ to the solution by applying a positive potential. Nevertheless, the authors do not provide sorption data to support their claim for the highly efficient capture of $\mathrm{Pb}^{2+}$ by MIL-101-Cr. The relationship of the concentration with the peak current was linear in the range from $1.0 \times 10^{-9}$ to $1.0 \times$ $10^{-6} \mathrm{M}$, with a low limit of detection of $5.0 \times 10^{-10} \mathrm{M}$ (well below the defined limit of $4.8 \times 10^{-8} \mathrm{M}$ by U.S. EPA). The presence of excess concentrations of potentially interfering ions does not seem to influence the electrochemical activity of the modified electrode to detect $\mathrm{Pb}^{2+}$. In addition, this sensor is capable of determining $\mathrm{Pb}^{2+}$ in rain and river water samples, with a recovery rate similar to that achieved by the Inductively Coupled Plasma-Mass Spectroscopy (ICP-MS) method.

$\mathrm{A} \mathrm{Ni}^{2+}$ MOF-based modifier $\left[\mathrm{Ni}\left(\mathrm{NH}_{2}-\mathrm{BDC}\right)\left(\mathrm{H}_{2} \mathrm{O}\right)\right]_{n}$ was synthesized through a facile one-pot hydrothermal reaction of $\mathrm{Ni}\left(\mathrm{NO}_{3}\right)_{2} \cdot 6 \mathrm{H}_{2} \mathrm{O}$ with $\mathrm{NH}_{2}-\mathrm{BDCH}_{2}$ in a mixture of $\mathrm{DMF} /$ water and was incorporated on a GCE for the determination of $\mathrm{Pb}^{2+} \cdot{ }^{65}$ PXRD data for this material confirm its crystalline nature; however, the exact structure of this compound has not been identified. Nevertheless, the PXRD patterns of this Ni-MOF, obtained after its treatment with aqueous solutions of various $\mathrm{pH}$ values, are similar to those of the as-prepared material, thus revealing its significant hydrolytic stability. The electro-

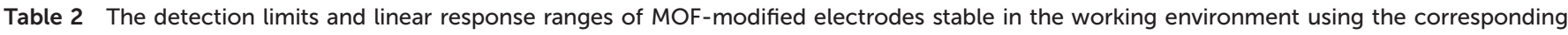
inorganic analytes and detection methods

\begin{tabular}{|c|c|c|c|c|c|}
\hline Sensor & Analyte & Linear range (M) & Detection limit (M) & Detection method & Ref. \\
\hline MIL-101-Cr/GCE & $\mathrm{Pb}^{2+}$ & $1.0 \times 10^{-9}-1.0 \times 10^{-6}$ & $5.0 \times 10^{-10}$ & DPASV & 62 \\
\hline Ni-MOF/GCE & $\mathrm{Pb}^{2+}$ & $5.0 \times 10^{-7}-6.0 \times 10^{-6}$ & $5.08 \times 10^{-7}$ & SWASV & 65 \\
\hline $\mathrm{Au} / \mathrm{Me}_{2} \mathrm{NH}_{2} @ \mathrm{MOF}-1 / \mathrm{GCE}$ & $\mathrm{Cu}^{2+}$ & $5.0 \times 10^{-12}-9.0 \times 10^{-7}$ & $1.0 \times 10^{-12}$ & SWASV & 70 \\
\hline TMU-16-NH ${ }_{2} / \mathrm{Gr} / \mathrm{CPE}$ & $\mathrm{Cd}^{2+}$ & $6.2 \times 10^{-12}-1.0 \times 10^{-9}$ & $1.7 \times 10^{-12}$ & DPASV & 66 \\
\hline UiO-66-NH $\mathrm{NH}_{2} @ P A N I / G C E$ & $\mathrm{Cd}^{2+}$ & $4.4 \times 10^{-12}-5.3 \times 10^{-9}$ & $2.6 \times 10^{-12}$ & DPASV & 69 \\
\hline SPAN@UIO-66-NH ${ }_{2} / \mathrm{SPCE}$ & $\mathrm{Cd}^{2+}$ & $4.4 \times 10^{-12}-8.9 \times 10^{-10}$ & $1.5 \times 10^{-12}$ & SWASV & 71 \\
\hline $\mathrm{NH}_{2}-\mathrm{MIL}-125-\mathrm{Ti} / \mathrm{CPE}$ & $\mathrm{Mn}^{2+}$ & $1.0 \times 10^{-8}-1.0 \times 10^{-5}$ & $4.0 \times 10^{-9}$ & Photoirradiation-CSV & 72 \\
\hline \multirow[t]{4}{*}{ GA-UiO-66- $\mathrm{NH}_{2} / \mathrm{GCE}$} & $\mathrm{Cd}^{2+}$ & $6.0 \times 10^{-8}-3.0 \times 10^{-6}$ & $2.0 \times 10^{-8}$ & \multirow[t]{4}{*}{ DPASV } & \multirow[t]{4}{*}{74} \\
\hline & $\mathrm{Pb}^{2+}$ & $1.0 \times 10^{-8}-4.0 \times 10^{-6}$ & $1.5 \times 10^{-9}$ & & \\
\hline & $\mathrm{Cu}^{2+}$ & $1.0 \times 10^{-7}-3.5 \times 10^{-6}$ & $7.0 \times 10^{-9}$ & & \\
\hline & $\mathrm{Hg}^{2+}$ & $5.0 \times 10^{-9}-3.0 \times 10^{-6}$ & $2.0 \times 10^{-9}$ & & \\
\hline \multirow[t]{4}{*}{ Ca-MOF/GPE } & $\mathrm{Pb}^{2+}$ & $4.8 \times 10^{-11}-2.3 \times 10^{-10}$ & $3.0 \times 10^{-12}$ & \multirow[t]{4}{*}{ SWASV } & \multirow[t]{4}{*}{78} \\
\hline & $\mathrm{Cd}^{2+}$ & $8.9 \times 10^{-11}-5.3 \times 10^{-10}$ & $1.1 \times 10^{-11}$ & & \\
\hline & $\mathrm{Cu}^{2+}$ & $1.5 \times 10^{-10}-9.4 \times 10^{-10}$ & $2.2 \times 10^{-11}$ & & \\
\hline & $\mathrm{Zn}^{2+}$ & $1.5 \times 10^{-10}-9.1 \times 10^{-10}$ & $1.6 \times 10^{-11}$ & & \\
\hline
\end{tabular}


chemical response of this sensor, denoted as Ni-MOF/GCE, was investigated towards $\mathrm{Pb}^{2+}$ via square wave anodic stripping voltammetry (SWASV). The oxidation current peak was increased linearly in a concentration range from $5.0 \times 10^{-7}$ to $6.0 \times 10^{-6} \mathrm{M}$. The limit of detection was estimated to be $5.08 \times$ $10^{-7} \mathrm{M}$, which is 10 times higher than the established limit by U.S. EPA for $\mathrm{Pb}^{2+}$ ions in drinking water. The Ni-MOF modifier seems to play the key role in the electrochemical analysis of $\mathrm{Pb}^{2+}$, as indicated by the comparative study with the unmodified GCE, where the oxidation current peak and, consequently, the determination ability for lead ions decreased. It is possible that $\mathrm{Pb}^{2+}$ interacts with the $\mathrm{NH}_{2}$-groups of the $\mathrm{Ni}$-MOF, thus resulting in enhanced pre-concentration for the Ni-MOF/GCE vs. the unmodified GCE. However, no $\mathrm{Pb}^{2+}$ sorption data were provided. The electrochemical characterization of the modified sensor was also performed, in which important operational parameters such as $\mathrm{pH}$, deposition potential, and deposition time were optimized to detect trace amounts of $\mathrm{Pb}^{2+}$ ions. In addition, the ability of the electrode to detect selectively lead ions was studied in the presence of a 10-fold excess of $\mathrm{Cr}^{3+}$, $\mathrm{Cu}^{2+}$, and $\mathrm{Cd}^{2+}$. No significant modification of the peak current of $\mathrm{Pb}^{2+}$ was observed in the presence of the above interfering cations, indicating efficient selectivity of the sensor for $\mathrm{Pb}^{2+}$.

ii. $\mathbf{C d}^{2+}$ sensing studies. A $\mathrm{Zn}^{2+}$-based MOF sensor was fabricated for the detection of traces of $\mathrm{Cd}^{2+}$ via differential pulse anodic stripping voltammetry (DPASV). Specifically, the MOF TMU-16- $\mathrm{NH}_{2}\left\{\left[\mathrm{Zn}_{2}\left(\mathrm{NH}_{2}-\mathrm{BDC}\right)_{2}(4-\mathrm{bpdh})\right] \cdot 3 \mathrm{DMF}\right.$, with 4-bpdh = 2,5-bis(4-pyridyl)-3,4-diaza-2,4-hexadiene\} was prepared via solvothermal reaction of $\mathrm{Zn}\left(\mathrm{NO}_{3}\right)_{2}, 4$-bpdh and $\mathrm{NH}_{2}-\mathrm{BDCH}_{2}$ in DMF. The crystal structure of TMU-16- $\mathrm{NH}_{2}$ is based on paddlewheel dinuclear zinc carboxylate units $\left[\mathrm{Zn}_{2}(\mathrm{COO})_{4}\right]$ bridged by $\mathrm{NH}_{2}-\mathrm{BDC}^{2-}$ ligands, resulting in a distorted 2D square grid. The 2D square grids are pillared by 4-bpdh ligands thus giving rise to a $3 \mathrm{D}$ framework. A modified CPE was prepared with a mixture of TMU-16- $\mathrm{NH}_{2}$ MOF and graphene (Gr) (TMU-16$\left.\mathrm{NH}_{2} / \mathrm{Gr} / \mathrm{CPE}\right) .{ }^{6}$ Owing to its unique properties which include its large surface area, high electrical conductivity and rapid heterogeneous electron transfer, Gr was used to improve the quantification limit of the modified electrode. A detailed study on the electrochemical properties of CPE/Gr, TMU-16/CPE/Gr (TMU-16 contains no $-\mathrm{NH}_{2}$ functional groups, otherwise it is isostructural to TMU-16- $\mathrm{NH}_{2}$ ) and TMU-16- $\mathrm{NH}_{2} / \mathrm{Gr} / \mathrm{CPE}$ showed a significantly higher response of the latter sensor towards $\mathrm{Cd}^{2+}$ ions. A good linear relationship was found between the peak currents and the concentration of $\mathrm{Cd}^{2+}$ over the range from $6.2 \times 10^{-12}$ to $1.0 \times 10^{-9} \mathrm{M}$ for the TMU-16$\mathrm{NH}_{2} / \mathrm{Gr} / \mathrm{CPE}$ sensor. The limit of detection was calculated to be $1.7 \times 10^{-12} \mathrm{M}$, well below the acceptable limit of $\mathrm{Cd}^{2+}$ in water (defined as $4.45 \times 10^{-8} \mathrm{M}$ by U.S. EPA). The repeatability of the sensor and its selectivity to detect $\mathrm{Cd}^{2+}$ sensitively in the presence of other competitive ions were also evaluated. The excellent $\mathrm{Cd}^{2+}$ sensing properties of the TMU-16- $\mathrm{NH}_{2} / \mathrm{Gr} / \mathrm{CPE}$ are probably attributed to the porous structure of the MOF modifier and the electron-donating amine groups that act as binding sites for the $\mathrm{Cd}^{2+}$ ions, thus greatly facilitating the pre- concentration of $\mathrm{Cd}^{2+}$ on the electrode. Nevertheless, neither $\mathrm{Cd}^{2+}$ sorption studies nor hydrolytic stability investigations were conducted for the TMU-16- $\mathrm{NH}_{2}$ MOF.

UiO-66- $\mathrm{NH}_{2}$ was coated with the polyaniline polymer (PANI) and was used as a modifier on a GCE for the detection of $\mathrm{Cd}^{2+}$ via DPASV. ${ }^{67}$ UiO- $\mathrm{NH}_{2}$ is quite stable in aqueous solutions and also shows significant sorption capacity for heavy metals. ${ }^{68}$ On the other hand, PANI can effectively increase the conductivity of composite materials by inducing the electron transfer between the solution and the electrode surface. The contribution of these materials on the GCE resulted in a reliable and highly sensitive electrochemical sensor with a detection limit for cadmium ions as low as $2.6 \times 10^{-12} \mathrm{M}$ and a linear increase in the current peak, when the $\mathrm{Cd}^{2+}$ concentration was between $4.4 \times 10^{-12}$ and $5.3 \times 10^{-12} \mathrm{M}$. The repeatability and the reproducibility of the usage of the UiO-66- $\mathrm{NH}_{2} @ \mathrm{PANI} / \mathrm{GCE}$ for $\mathrm{Cd}^{2+}$ analysis were also studied. Moreover, the study on the interfering effects of several common coexisting ions revealed that only $\mathrm{Cu}^{2+}$ with a concentration higher than $7.87 \times 10^{-10} \mathrm{M}$ could affect the electrochemical response of the sensor, due to the competition between $\mathrm{Cu}^{2+}$ and $\mathrm{Cd}^{2+}$ at the active sorption sites.

Very recently, a screen-printed carbon electrode (SCPE) based on UiO- $\mathrm{NH}_{2}$ and self-doped polyaniline nanofibers (SPAN) copolymerized with aniline (AN) and $m$-aminobenzenesulfonic acid (SAN) was prepared for the detection of trace levels of $\mathrm{Cd}^{2+} \cdot{ }^{69}$ In contrast to PANI, which is conductive only in its protonated form or under low $\mathrm{pH}$ values, SPAN display high electrical conductivities, large specific surface areas, and relevant hydrophilicities, which are particularly useful features for the construction of electrochemical sensors. The synthetic procedure of SPAN@UIO-66- $\mathrm{NH}_{2}$ consists of two steps: (1) preparation of UIO-66- $\mathrm{NH}_{2}$ and (2) coating of UIO-66- $\mathrm{NH}_{2}$ with SPAN at controlled low-temperature by self-assembly technology (Fig. 4). The efficiency of the modified electrochemical sensor SPAN@UIO-66- $\mathrm{NH}_{2} / \mathrm{SPCE}$ to determine $\mathrm{Cd}^{2+}$ was determined by the SWASV method. Under optimized conditions, the response current of $\mathrm{Cd}^{2+}$ increased linearly with an



Fig. 4 Schematic representation of the synthetic route of UiO- $\mathrm{NH}_{2}$, core-shell SPAN@UIO-66- $\mathrm{NH}_{2}$ and core-shell SPAN@UIO-66- $\mathrm{NH}_{2}$. Reprinted from ref. 69 with permission from The Electrochemical Society. 
increase in the concentration in the range from $4.4 \times 10^{-12}$ to $8.9 \times 10^{-10} \mathrm{M}$, with the detection limit found to be as low as $1.5 \times 10^{-12} \mathrm{M}$. The stability and the repeatability of the proposed sensor, as well as its applicability in real water and urine samples, were also demonstrated.

iii. $\mathrm{Cu}^{2+}$ sensing studies. A novel microporous zinc-based MOF, namely $\mathrm{Me}_{2} \mathrm{NH}_{2} @ M O F-1 \quad\left\{\left[\mathrm{H}_{2} \mathrm{~N}\left(\mathrm{CH}_{3}\right)_{2}\right]_{4}\left[\mathrm{Zn}_{3}(\mathrm{Hdpa})_{2}\right]\right.$. 4DMF, with $\mathrm{H}_{6}$ dpa = 3,4-di(3,5-dicarboxyphenyl)phthalic acid, $\mathrm{DMF}=$ dimethylformamide $\}$, was prepared via the reaction of $\mathrm{Zn}$ (II) acetate and $\mathrm{H}_{6} \mathrm{dpa}$ in $\mathrm{DMF} / \mathrm{H}_{2} \mathrm{O} / \mathrm{HNO}_{3}$ under solvothermal conditions and was used for the modification of a GCE. ${ }^{70}$ The anionic framework of $\mathrm{Me}_{2} \mathrm{NH}_{2} @ \mathrm{MOF}-1$ contains subunits, each of which consists of two independent $\mathrm{Zn}$ (II) atoms (Zn1 and Zn2). Two Zn1 and four Zn2 atoms are connected by six ligands to form a cage with dimensions of $9.4 \times$ $13.6 \AA$, while the channels are filled with $\left[\mathrm{H}_{2} \mathrm{~N}\left(\mathrm{CH}_{3}\right)_{2}\right]^{+}$ions to balance the charge. A GCE was modified with Au nanoparticles and $\mathrm{Me}_{2} \mathrm{NH}_{2} @ M O F-1$. This modified electrode, denoted as $\mathrm{Au} /$ $\mathrm{Me}_{2} \mathrm{NH}_{2} @ \mathrm{MOF}-1 / \mathrm{GCE}$, was proved to be an excellent sensor for the detection of $\mathrm{Cu}^{2+}$ via SWASV (Fig. 5).

A linear increase in the peak current was observed for $\mathrm{Cu}^{2+}$ concentrations in the range of $5.0 \times 10^{-12}$ to $9.0 \times 10^{-7} \mathrm{M}$. The detection limit was found to be $1.0 \times 10^{-12} \mathrm{M}$, which is quite lower than the established limit $\left(1.57 \times 10^{-5} \mathrm{M}\right)$ for copper(II) by the U.S. EPA and the World Health Organization (WHO). ${ }^{71}$ A comparison study among the bare GCE, Au/GCE, $\mathrm{Me}_{2} \mathrm{NH}_{2} @ \mathrm{MOF}-1 / \mathrm{GCE}$ and $\mathrm{Au} / \mathrm{Me}_{2} \mathrm{NH}_{2} @ \mathrm{MOF}-1 / \mathrm{GCE}$ revealed that the latter demonstrated greater electrochemical response to $\mathrm{Cu}^{2+}$. Moreover, the sensitivity and selectivity of the modified electrode were confirmed in the presence of several interfering ions and in river water samples, indicating a promising sensor for real environmental water sample analyses. According to the authors, anionic $\mathrm{Me}_{2} \mathrm{NH}_{2} @ \mathrm{MOF}-1$ can

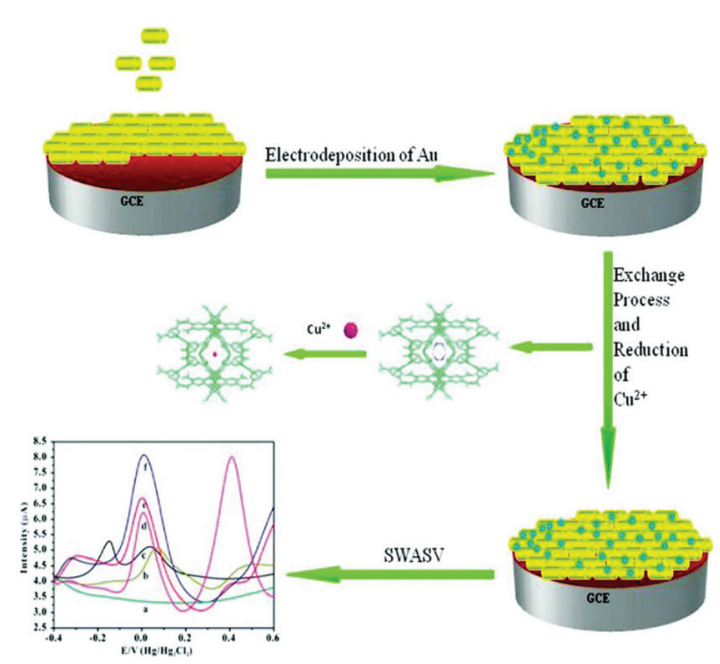

Fig. 5 Schematic representation of the preparation process of the Au/ $\mathrm{Me}_{2} \mathrm{NH}_{2}$ @MOF-1/GCE and the procedures for determination of copper (II) via the cation exchange and nano-particle synergy effect enhanced electrochemical signal. Reproduced from ref. 70 with permission from the Royal Society of Chemistry. exchange $\left[\mathrm{H}_{2} \mathrm{~N}\left(\mathrm{CH}_{3}\right)_{2}\right]^{+}$ions with $\mathrm{Cu}^{2+}$ thus enhancing the preconcentration of $\mathrm{Cu}^{2+}$ traces and greatly increasing the analytical signal, while $\mathrm{Au}$ acts as a binder. Nevertheless, the proposed sensing mechanism is not supported by experimental data, as no $\mathrm{Cu}^{2+}$ sorption data are reported for $\mathrm{Me}_{2} \mathrm{NH}_{2} @$ MOF-1 and the hydrolytic stability of the MOF has not been investigated.

iv. $\mathrm{Mn}^{2+}$ sensing studies. Another example of MOF used as modifier in CPE was $\mathrm{NH}_{2}$-MIL-125-Ti $\left[\mathrm{Ti}_{8} \mathrm{O}_{8}(\mathrm{OH})_{4}\left(\mathrm{NH}_{2}-\mathrm{BDC}\right)_{6}\right]$. $\mathrm{NH}_{2}$-MIL-125-Ti was synthesized via a solvothermal reaction of tetrabutyl titanate and $\mathrm{NH}_{2}-\mathrm{BDCH}_{2}$ in $\mathrm{DMF} /$ methanol. The structure of $\mathrm{NH}_{2}$-MIL-125-Ti is based on $\mathrm{Ti}_{8}$ cyclic octanuclear clusters linked via $\mathrm{NH}_{2}-\mathrm{BDC}^{2-}$ ligands to result in a 3-D microporous framework. SEM microscopy revealed particles with a disk-like shape and uniform particle size distribution around $300 \mathrm{~nm}$. The stability of $\mathrm{NH}_{2}$-MIL-125-Ti in water and its efficiency of reproducible adsorption and desorption isotherms after many water cycles, have been reported in detail. ${ }^{72}$ The fabrication of the $\mathrm{NH}_{2}-\mathrm{MIL}-125-\mathrm{Ti} / \mathrm{CPE}$ was carried out by mixing the MOF with grade graphite powder in paraffin oil. The modified electrode was applied for the determination of $\mathrm{Mn}^{2+}$ in aqueous solutions. Although manganese is an essential microelement for the human body that is not classified as a toxic element, high concentrations of $\mathrm{Mn}^{2+}$ are related to some diseases such as Parkinson's disease. ${ }^{73}$

Therefore, the determination of manganese is of vital importance. The modified $\mathrm{NH}_{2}$-MIL-125-Ti/CPE revealed favorable detection ability for $\mathrm{Mn}^{2+}$ in water, with a low detection limit of $4.0 \times 10^{-9} \mathrm{M}$ (well below the defined limit of $9.1 \times 10^{-7}$ $\mathrm{M}$ by U.S. EPA) and a linear regression equation for manganese in the concentration range from $1.0 \times 10^{-8}$ to $1.0 \times 10^{-5}$ M. The determination of $\mathrm{Mn}^{2+}$ was achieved by CSV, after light irradiation of the samples for about $20 \mathrm{~min}$. The proposed mechanism for the detection of manganese is based on (a) the oxidation of $\mathrm{Mn}^{2+}$ to $\mathrm{MnO}_{2}$ by the electron holes formed upon light irradiation of $\mathrm{NH}_{2}$-MIL-125-Ti and (b) reduction of the deposited $\mathrm{MnO}_{2}$ to $\mathrm{Mn}^{2+}$ during the cathodic stripping step (Fig. 6). Many important parameters to acquire the best electrochemical response were investigated in detail, including the mass percentage of the MOF, the $\mathrm{pH}$ of the supporting electrolytes and the photoirradiation time for the response of the sensor. Finally, the modified CPE was applied for determination of $\mathrm{Mn}^{2+}$ in various tea samples showing similar results to those obtained via the flame atomic absorption spectroscopic method (FAAS).

\subsection{Multiple analyte determination}

A UiO-66- $\mathrm{NH}_{2} / \mathrm{GA}$ (GA = graphene aerogel) composite was isolated via the in situ growth of the MOF on the GA matrix and the composite was applied on a GCE, for individual and for simultaneous determination of $\mathrm{Cd}^{2+}, \mathrm{Pb}^{2+}, \mathrm{Cu}^{2+}$ and $\mathrm{Hg}^{2+}$ in water samples (Fig. 7). ${ }^{74}$ GA enhances the conductivity of the composite material and speeds up the electron diffusion in the matrix. The determination of the examined heavy metals was achieved by DPASV. 



Fig. 6 (A) The photooxidation procedure of $\mathrm{Mn}^{2+}$ at the $\mathrm{NH}_{2}-\mathrm{MIL}-125-$ $\mathrm{Ti} / \mathrm{CPE}$ and its determination by CSV. (B) Schematic illustration of the structure of the $\mathrm{NH}_{2}-\mathrm{MIL}-125$ (Ti) modified carbon paste electrode. Reprinted from ref. $72 d$ with permission from Elsevier.

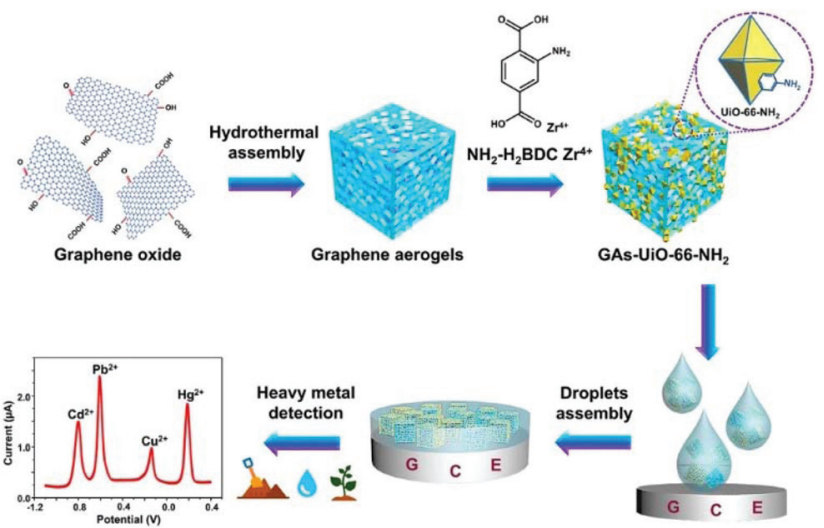

Fig. 7 Synthesis of the GAs-UiO-66- $\mathrm{NH}_{2}$ composite via the in situ growth of the UiO-66- $\mathrm{NH}_{2}$ crystal on the GAs Matrix and the determination of heavy metal ions with the modified electrode. Reprinted from ref. 74 with permission from American Chemical Society.

The linear ranges for the determination were $6.0 \times 10^{-8}$ to

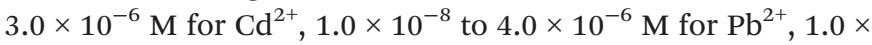
$10^{-7}$ to $3.5 \times 10^{-6} \mathrm{M}$ for $\mathrm{Cu}^{2+}$, and $5.0 \times 10^{-9}$ to $3.0 \times 10^{-6} \mathrm{M}$ for $\mathrm{Hg}^{2+}$. The limits of detection for each metal ion were found to be $2.0 \times 10^{-8} \mathrm{M}$ for $\mathrm{Cd}^{2+}, 1.5 \times 10^{-9} \mathrm{M}$ for $\mathrm{Pb}^{2+}, 7.0 \times 10^{-9} \mathrm{M}$ for $\mathrm{Cu}^{2+}$ and $2.0 \times 10^{-9} \mathrm{M}$ for $\mathrm{Hg}^{2+}$. The detection limits are below the acceptable limits of these metal ions in water. Furthermore, the electrochemical response of the GA-UiO-66$\mathrm{NH}_{2}$ /GCE was explored in the presence of all four examined ions. The results revealed lower sensitivity for simultaneous determination, since a narrower linear range, lower slope and in the case of $\mathrm{Cu}^{2+}$ a relatively higher limit of detection were observed, probably due to the interactions between different metals such as competitive deposition and formation of intermetallic compounds. ${ }^{75,76}$ Moreover, a weak peak that appeared between $\mathrm{Pb}^{2+}$ and $\mathrm{Cu}^{2+}$ may be attributed to the formation of
$\mathrm{Pb}-\mathrm{Cu}$ intermetallic compounds during the deposition step. ${ }^{76,77}$ Taking into account the excellent results which emerged from the studies in the presence of competitive ions and from studies with real samples, including river water, soil, and vegetables (spinach), the proposed sensor seems promising for accurate and reliable monitoring of toxic heavy metal ions under various conditions.

Very recently, our groups reported a simple ready-to-use electrochemical sensor based on graphite paste modified with the Ca-MOF $\left\{\left[\mathrm{Ca}\left(\mathrm{H}_{4} \mathrm{~L}\right)(\mathrm{DMA})_{2}\right] \cdot 2 \mathrm{DMA}\right.$, with $\mathrm{H}_{6} \mathrm{~L}=N, N^{\prime}$-bis $(2,4-$ dicarboxyphenyl)-oxalamide\}, which can be used for the detection of trace levels of $\mathrm{Pb}^{2+}, \mathrm{Cd}^{2+}, \mathrm{Cu}^{2+}$ and $\mathrm{Zn}^{2+}$ in aqueous solutions via SWASV. ${ }^{78 a}$ Single crystals of the Ca-MOF were obtained after the reaction of $\mathrm{Ca}\left(\mathrm{NO}_{3}\right)_{3} \cdot 4 \mathrm{H}_{2} \mathrm{O}$ with $\mathrm{H}_{6} \mathrm{~L}$ in DMA under solvothermal conditions at $100{ }^{\circ} \mathrm{C} .{ }^{78 b}$ The asymmetric unit of Ca-MOF comprises one half of $\mathrm{H}_{4} \mathrm{~L}^{2-}$, one half of a $\mathrm{Ca}^{2+}$ ion and two DMA molecules. The $\mathrm{H}_{4} \mathrm{~L}^{2-}$ ligand bridges four $\mathrm{Ca}^{2+}$ ions through two carboxylate and two carboxylic $\mathrm{O}$ atoms to form a 2D framework (Fig. 8).

Our motivation to use the Ca-MOF as a chemical modifier in electrodes for the determination of heavy metals was the excellent capability of this material for efficient and selective sorption of $\mathrm{Pb}^{2+}, \mathrm{Cd}^{2+}, \mathrm{Cu}^{2+}$ and $\mathrm{Zn}^{2+}$ in aqueous media (due to the rapid exchange of $\mathrm{Ca}^{2+}$ ions by other metal ions) and its significant hydrolytic stability. Specifically, the Ca-MOF displays some of the highest sorption capacities reported for $\mathrm{Pb}^{2+}$ $\left(522 \mathrm{mg} \mathrm{g}^{-1}\right)$ and $\mathrm{Cd}^{2+}\left(220 \mathrm{mg} \mathrm{g}^{-1}\right)$. In addition, the sorption capability of the Ca-MOF for these heavy metal ions is not influenced by the presence of common competitive ions (e.g. $\mathrm{Ca}^{2+}, \mathrm{Na}^{+}$). Furthermore, the Ca-MOF shows appreciable sorption capability for $\mathrm{Zn}^{2+}$ and $\mathrm{Cu}^{2+}$. The stability of the Ca-MOF in water was demonstrated via ${ }^{1} \mathrm{H}$ NMR data revealing no leaching of the $\mathrm{H}_{4} \mathrm{~L}^{2-}$ ligands, even in the presence of metal ions. The limits of detection using the Ca-MOF/CPE sensor were estimated to be $3.0 \times 10^{-12} \mathrm{M}$ for $\mathrm{Pb}^{2+}, 2.2 \times 10^{-11} \mathrm{M}$ for $\mathrm{Cu}^{2+}, 1.6 \times 10^{-11} \mathrm{M}$ for $\mathrm{Zn}^{2+}$ and $1.1 \times 10^{-11} \mathrm{M}$ for $\mathrm{Cd}^{2+}$, which



Fig. 8 Schematic illustration of the structure of the Ca-MOF. Several $\mathrm{H}$ atoms have been removed for clarity. Color code: $\mathrm{Ca}$, green; $\mathrm{C}$, grey; $\mathrm{O}$, red; $\mathrm{N}$, blue; and $\mathrm{H}$, cyan. Reproduced from ref. $78 \mathrm{~b}$ with permission from the Royal Society of Chemistry. 


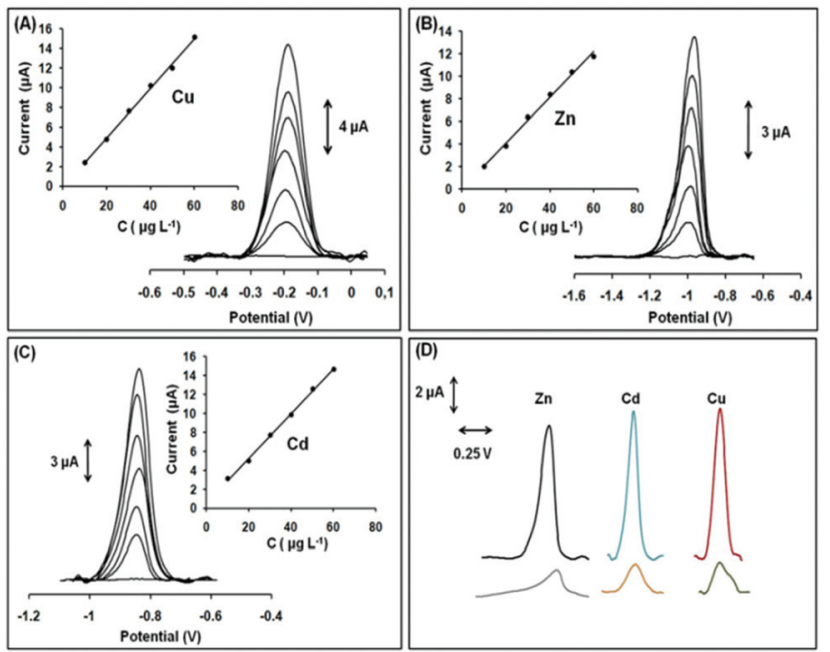

Fig. 9 SWASV voltammograms and respective calibration plots in the range $10-60 \mu \mathrm{g} \mathrm{L}^{-1}$ (step: $10 \mu \mathrm{g} \mathrm{L}^{-1}$ ) of (A) $\mathrm{Cu}^{2+}$ in $0.1 \mathrm{~mol} \mathrm{~L}^{-1}$ acetate buffer, (B) $\mathrm{Zn}^{2+}$ in $1 \times 10^{-3} \mathrm{~mol} \mathrm{~L}^{-1} \mathrm{KCl}$, and (C) $\mathrm{Cd}^{2+}$ in $0.1 \mathrm{~mol} \mathrm{~L}^{-1}$ acetate buffer ( $\mathrm{pH}$ 4.5). (D) SWASV voltammograms of $30 \mu \mathrm{g} \mathrm{L}^{-1}$ of $\mathrm{Zn}^{2+}$, $\mathrm{Cd}^{2+}, \mathrm{Cu}^{2+}$ (black, blue, and red lines, respectively) obtained with the modified GPE with Ca-MOF and SWASV voltammograms of $30 \mu \mathrm{g} \mathrm{L}^{-1}$ of $\mathrm{Zn}^{2+}, \mathrm{Cd}^{2+}$, and $\mathrm{Cu}^{2+}$ (gray, orange, and green lines, respectively) obtained with the bare GPE. Reproduced from ref. 78a with permission from the Royal Society of Chemistry.

were comparable to, or lower than, those of other electrochemical sensors (Fig. 9). ${ }^{79}$

Compared to conventional electrochemical sensors, this modified electrode can effectively detect $\mathrm{Cu}^{2+}$ (normally not possible since the oxidation peak of $\mathrm{Cu}$ appears outside the useful potential window of these electrodes), is able to detect simultaneously multiple heavy metal ions and is ready-to-use, i.e. it does not demand multistep reconstruction between the electrochemical measurements. Interestingly, the Ca-MOF modified electrode represents the first MOF-based sensor for the voltammetric determination of trace amounts of $\mathrm{Zn}^{2+}$.

\section{Comparison of MOFs with other types of electrode modifiers}

As mentioned in the introduction, there are a number of materials that have been tested as electrode modifiers, such as zeolites, clays, graphene, Au NPs, mesoporous silica and so on, for the fabrication of electrodes to be used for the determination of inorganic analytes (mainly heavy metal ions) via voltammetric techniques. ${ }^{80}$ These modifiers enhance the pre-concentration efficiency of the electrodes (mainly carbon paste or glassy carbon electrodes) resulting in particularly low detection limits (in the range $10^{-8}-10^{-12} \mathrm{M}$ ) for the inorganic species.

The analysis of the organic species is mainly done by modifying the glassy carbon electrodes (GCEs) which have been used as substrates for modification due to their inherent advantages such as a wide potential window, low background currents and chemical stability. The modification of GCEs takes place in order to construct more selective and more sensitive electrodes. For this purpose, there have been several reports on GCEs modified with carbon nanotubes, ${ }^{81}$ nanoparticles $^{82}$ and polymers ${ }^{83}$ for the detection of organic molecules of biological interest such as dopamine, uric acid and ascorbic acid. For example, a typical single-walled carbon nanotube (SWCNT) $/ \mathrm{GCE}^{81 a}$ exhibited a good linear working range of $0.01-0.20 \times 10^{-6} \mathrm{M}$ with the detection limit estimated to be $15 \times 10^{-6} \mathrm{M}$ for dopamine determination. A common nanoparticle modified electrode ${ }^{82 d}$ for the detection of the same analyte exhibited a linear range response of $0.5-30 \times$ $10^{-6} \mathrm{M}$ and a detection limit at $0.011 \times 10^{-6} \mathrm{M}$. Organic polymer modified electrodes ${ }^{83 d}$ also responded well exhibiting a similar linear range for the detection of dopamine and almost the same limits of detection as those mentioned above were achieved.

MOFs have been recently employed as modifiers in electrodes to be used for trace analysis of heavy metal ions and organic species. MOF-modified electrodes have achieved detection limits comparable to those obtained with the other types of modified electrodes (see above). Nevertheless, the research on MOF-electrode modifiers is at an early stage since there is plenty of room for the optimization of their properties, as will be discussed in the next section. The fact that the properties of MOFs can be easily tuned by applying targeted modifications in the structures of known MOFs or designing new MOFs with appropriate structural features is a major advantage of MOFs compared to other types of modifiers. ${ }^{1}$ Furthermore, the high crystallinity of MOFs allows precise structural determination of MOFs loaded with analytes, which can facilitate the identification of analyte-MOF interactions and, thus, the design of MOFs with appropriate characteristics for efficient sorption capability and selectivity for the targeted analyte. ${ }^{84}$ The latter is particularly important for the utilization of a material as an electrode modifier, as it is directly related to the pre-concentration efficiency of the working electrode. The main disadvantage of MOFs for their extended use in electroanalytical applications is related to their poor electrical conductivities; however, this drawback of MOFs can be overcome by either mixing them with conductive materials (e.g. conductive graphite powder) or transforming them to composites with conductive polymers (e.g. PANI). ${ }^{69,71,78}$

\section{Conclusions and prospects}

The above discussion revealed that MOFs are highly promising as modifiers for electrodes that can be used for determination of trace amounts of inorganic and organic analytes via voltammetric techniques. The enhanced performance of MOF-modified electrodes is largely attributed to the intrinsic properties of MOFs such as their high surface area, larger pore size, ability to adsorb the analytes from solution, better distribution-exposure and loading, immobilization-stabilization of electrocatalytic centers (e.g. metal NPs) that may be utilized 
etc. All the above can be realized only in cases in which the MOFs maintain their structural stability during the electrode fabrication and performance. Nevertheless, in several cases, MOFs that were chosen to modify electrodes did not satisfy the basic features of appropriate electrode modifiers, i.e. stability under the conditions of analyses and sorption capability towards the targeted analyte. We thus propose that prior to the choice of a MOF to be used as an electrode modifier the following three steps should be followed (Scheme 1):

1. Rational design and synthesis of a MOF possessing structural features (e.g. pore size and functional groups) that will lead to high affinity for a specific analyte.

2. Investigation of the structural stability of the MOF under the conditions of analyses (i.e. spectroscopic, analytical and PXRD studies of the MOF after its treatment with solutions having similar compositions to those of samples that will be analysed), in order to avoid using MOFs that either decompose or dissolve under the working conditions, thus leaching unwanted chemical species in the working media.

3. Evaluation of the sorption capacity of the MOF towards the analyte of interest, under the premise that the MOF has been proved to be stable under the conditions of analyses (step 2).

We should note that the stability and sorption studies (steps 2 and 3 ) are of vital importance since these two elements are closely related to the determination of the mechanism of the whole electrochemical procedure which can result in the design of new and improved MOFs as electrode modifiers.

Therefore, there is a lot of future research to be performed aiming at obtaining MOF-modified electrodes with optimum performance. Attention should be paid to known MOFs with demonstrated structural stability under the conditions of analysis and efficient sorption capacity for various organic or inorganic species. Such materials are particularly suitable to be tested as electrode modifiers. Furthermore, new MOFs can also be synthesized by employing polytopic organic ligands with functionalities having high affinity for specific analytes. In addition, new alkaline or alkaline earth MOFs as electrode modifiers may be involved in facile cation exchange with toxic

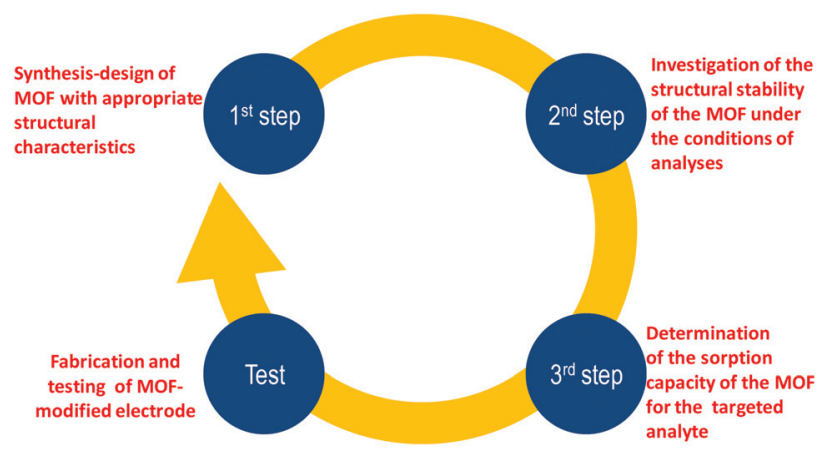

Scheme 1 The proposed steps that should be followed prior to the fabrication and testing of a successful MOF-modified electrode. heavy metal ions. All the above MOFs, showing efficient chemical stability and sorption capacity for the species of interest, may be then tested as electrode modifiers for voltammetric determination of trace analytes. We should also note that the development of optimum MOF-modified electrodes should involve a collaboration between inorganic synthetic chemists and analytical chemists with expertise in electroanalysis, since the optimization process requires both synthetic and analytical work. Overall, we believe that the research on MOF-modified electrodes will evolve rapidly over the coming years, as many researchers from various scientific disciplines will find this field of research particularly appealing for the development of new tools for trace analysis.

\section{Conflicts of interest}

There are no conflicts to declare.

\section{Acknowledgements}

The authors would like to thank Prof. M. Prodromidis (Department of Chemistry, University of Ioannina), Prof. A. Economou and Assistant Prof. C. Kokkinos (Department of Chemistry, National and Kapodistrian University of Athens) for fruitful discussions about voltammetric analysis.

\section{Notes and references}

1 (a) A. D. Katsenis, E. K. Brechin and G. S. Papaefstathiou, Encycl. Inorg. Bioinorg. Chem., 2014, 1-14; (b) Z. Hu, B. J. Deibert and J. Li, Chem. Soc. Rev., 2014, 43, 5815-5840; (c) L. E. Kreno, K. Leong, O. K. Farha, M. Allendorf, R. P. Van Duyne and J. T. Hupp, Chem. Rev., 2012, 112, 1105-1125; (d) S. Wang and X. Wang, Small, 2015, 11, 3097-3112; (e) H. Furukawa, U. Müller and O. M. Yaghi, Angew. Chem., Int. Ed., 2015, 54, 3417-3430; $(f)$ C. Wang, X. Liu, N. Keser Demir, J. P. Chen and K. Li, Chem. Soc. Rev., 2016, 45, 5107-5134; (g) P. Silva, S. M. F. Vilela, J. P. C. Tome and F. A. Almeida Paz, Chem. Soc. Rev., 2015, 44, 6774-6803; (h) P. Falcaro, R. Ricco, C. M. Doherty, K. Liang, A. J. Hill and M. J. Styles, Chem. Soc. Rev., 2014, 43, 5513-5560; (i) O. Shekhah, J. Liu, R. A. Fischer and C. Woell, Chem. Soc. Rev., 2011, 40, 1081-1106; (j) H. Furukawa, K. E. Cordova, M. O'Keeffe and O. M. Yaghi, Science, 2013, 341, 1230444.

2 S. A. Diamantis, A. Margariti, A. D. Pournara, G. S. Papaefstathiou, M. J. Manos and T. Lazarides, Inorg. Chem. Front., 2018, 5, 1493-1511.

3 (a) W. P. Lustig, S. Mukherjee, N. D. Rudd, A. V. Desai, J. Li and S. K. Ghosh, Chem. Soc. Rev., 2017, 46, 3242-3285; (b) D. Zhao, Y. Cui, Y. Yang and G. Qian, CrystEngComm, 2016, 18, 3746-3759; (c) Z. Hu, B. J. Deibert and J. Li, Chem. Soc. Rev., 2014, 43, 5815-5840; (d) Y. Zhang, S. Yuan, 
G. Day, X. Wang, X. Yang and H. C. Zhou, Coord. Chem. Rev., 2018, 354, 28-45; (e) P. Kumar, A. Deep and K. H. Kim, TrAC, Trends Anal. Chem., 2015, 73, 39-53.

4 (a) D. Harvey, Modern analytical chemistry, McGraw-Hill, 2000, pp. 508-531; (b) A. Economou and C. Kokkinos, Advances in Stripping Analysis of Metals, RSC Detection Science Series No. 6, Electrochemical Strategies in Detection Science, The Royal Society of Chemistry, 2016, pp. 1-18.

5 (a) Y. Wang, Y. Wu, J. Xie, H. Ge and X. Hu, Analyst, 2013, 138, 5113-5120; (b) Y. Wang, H. Ge, Y. Wu, G. Ye, H. Chen and X. Hu, Talanta, 2014, 129, 100-105; (c) Y. Wang, Y. Wu, J. Xie and X. Hu, Sens. Actuators, B, 2013, 177, 1161-1166.

6 (a) N. C. Burtch, H. Jasuja and K. S. Walton, Chem. Rev., 2014, 114, 10575-10612; (b) J. B. DeCoste, G. W. Peterson, H. Jasuja, T. G. Glover, Y. G. Huang and K. S. Walton, J. Mater. Chem. A, 2013, 1, 5642-5650.

7 H. Xu, L. Zeng, S. Xing, Y. Xian, G. Shi and L. Jin, Electroanalysis, 2008, 20, 2655-2662.

8 (a) H. B. Herman, R. L. McNeely, P. Surana, C. M. Elliott and R. W. Murray, Anal. Chem., 1974, 46, 1258-1265; (b) Z. Yang, X. Huang, R. Zhang, J. Li, Q. Xu and X. Hu, Electrochim. Acta, 2012, 70, 325-330.

9 I. Švancara, K. Kalcher, A. Walcarius and K. Vytras, in Electroanalysis with carbon paste electrodes, CRC Press, 2012.

10 D. W. Pan, Y. E. Wang, Z. P. Chen, T. T. Lou and W. Qin, Anal. Chem., 2009, 81, 5088-5094.

11 L. Y. Cao, J. B. Jia and Z. H. Wang, Electrochim. Acta, 2008, 53, 2177-2182.

12 E. Svobodova-Tesarova, L. Baldrianova, M. Stoces, I. Svancara, K. Vytras, S. B. Hocevar and B. Ogorevc, Electrochim. Acta, 2011, 56, 6673-6677.

13 J. X. Guo, Y. Q. Chai, R. Yuan, Z. J. Song and Z. F. Zou, Sens. Actuators, B, 2011, 155, 639-645.

14 P. P. Dai and Z. S. Yang, Microchim. Acta, 2012, 176, 109115.

15 M. A. El Mhammedi, M. Achak and A. Chtaini, J. Hazard. Mater., 2009, 161, 55-61.

16 Y. Gómez, L. Fernández, C. Borrás, J. Mostany and B. Scharifker, Talanta, 2011, 85, 1357-1363.

17 P. K. Q. Nguyen and S. K. Lunsford, Talanta, 2012, 101, 110-121.

18 W. Wonsawat, S. Chuanuwatanakul, W. Dungchai, E. Punrat, S. Motomizu and O. Chailapakul, Talanta, 2012, 100, 282-289.

19 (a) M. F. Mousavi, A. Rahmani, S. M. Golabi, M. Shamsipur and H. Sharghi, Talanta, 2001, 55, 305-312; (b) Z. M. Hu, C. J. Seliskar and W. R. Heineman, Anal. Chim. Acta, 1998, 369, 93-101.

20 (a) O. K. Farha, I. Eryazici, N. C. Jeong, B. G. Hauser, C. E. Wilmer, A. A. Sarjeant, R. Q. Snurr, S. T. Nguyen, A. Ö. Yazaydın and J. T. Hupp, J. Am. Chem. Soc., 2012, 134, 15016-15021; (b) D. A. Gómez-Gualdrón, P. Z. Moghadam, J. T. Hupp, O. K. Farha and R. Q. Snurr, J. Am. Chem. Soc., 2016, 138, 215-224; (c) I. M. Hönicke, I. Senkovska, V. Bon,
I. A. Baburin, N. Bönisch, S. Raschke, J. D. Evans and S. Kaskel, Angew. Chem., Int. Ed., 2018, 57, 13780-13783.

21 Y. Sun, Y. Li, N. Wang, Q. Q. Xu, L. Xu and M. Lin, Electroanalysis, 2018, 30, 474-478.

22 J. Li, J. Xia, F. Zhang, Z. Wang and Q. Liu, J. Chin. Chem. Soc., 2018, 65, 743-749.

23 Z. Wang, B. Ma, C. Shen and L.-Z. Cheong, Talanta, 2019, 197, 356-362.

24 Y. Ming, N. Kumar and D. J. Siegel, ACS Omega, 2017, 2, 4921-4928.

25 L. N. McHugh, M. J. McPherson, L. J. McCormick, S. A. Morris, P. S. Wheatley, S. J. Teat, D. McKay, D. M. Dawson, C. E. F. Sansome, S. E. Ashbrook, C. A. Stone, M. W. Smith and R. E. Morris, Nat. Chem., 2018, 10, 1096-1102.

26 F. A. Sofi, M. A. Bhat and K. Majid, New J. Chem., 2019, 43, 3119-3127.

27 Y. Wang, W. Cao, L. Wang, Q. Zhuang and Y. Ni, Microchim. Acta, 2018, 185, 315.

28 (a) Q. Chen, X. Li, X. Min, D. Cheng, J. Zhou, Y. Li, Z. Xie, P. Liu, W. Cai and C. Zhang, J. Electroanal. Chem., 2017, 789, 114-122; (b) J. Li, J. Xia, F. Zhang, Z. Wang and Q. Liu, Talanta, 2018, 181, 80-86.

29 Y. Yang, Q. Wang, W. Qiu, H. Guo and F. Gao, J. Phys. Chem. C, 2016, 120, 9794-9803.

30 (a) D. Brondani, E. Zapp, R. da Silva Heying, B. de Souza and I. Cruz Vieira, Electroanalysis, 2017, 29, 2810-2817; (b) S. Dong, G. Suo, N. Li, Z. Chen, L. Peng, Y. Fu, Q. Yang and T. Huang, Sens. Actuators, B, 2016, 222, 972-979.

31 Y. Cao, L. Wang, C. Shen, C. Wang, X. Hu and G. Wang, Sens. Actuators, B, 2019, 283, 487-494.

32 C. Li, Y. Zhou, X. Zhu, B. Ye and M. Hu, Int. J. Electrochem. Sci., 2018, 4855-4867.

33 C. T. P. da Silva, F. R. Veregue, L. W. Aguiar, J. G. Meneguin, M. P. Moisés, S. L. Fávaro, E. Radovanovic, E. M. Girotto and A. W. Rinaldi, New J. Chem., 2016, 40, 8872-8877.

34 T. T. Minh, N. H. Phong, H. Van Duc and D. Q. Khieu, J. Mater. Sci., 2017, 53, 2453-2471.

35 Y. Shi, Y. Zhang, Y. Wang, H. Huang and J. Ma, Int. J. Electrochem. Sci., 2018, 13, 7643-7654.

36 P. Arul and S. A. John, J. Electroanal. Chem., 2017, 799, 6169.

37 H. Hosseini, H. Ahmar, A. Dehghani, A. Bagheri, A. Tadjarodi and A. R. Fakhari, Biosens. Bioelectron., 2013, 42, 426-429.

38 L. Hu, N. Wu, J. Zheng, J. Xu, M. Zhang and P. He, Anal. Sci., 2014, 30, 663-668.

39 S. Li, Y. Duan, S. Lei, J. Qiao, G. Li and B. Ye, Sens. Actuators, B, 2018, 274, 218-227.

40 Y. Bai, Y. Dou, L.-H. Xie, W. Rutledge, J.-R. Li and H.-C. Zhou, Chem. Soc. Rev., 2016, 45, 2327-2367.

41 N. Karimian, H. Fakhri, S. Amidi, A. Hajian, F. Arduini and H. Bagheri, New J. Chem., 2019, 43, 2600-2609.

42 M. Deng, S. Lin, X. Bo and L. Guo, Talanta, 2017, 174, 527538. 
43 (a) M. Chen, N. Gan, Y. Zhou, T. Li, Q. Xu, Y. Cao and Y. Chen, Sens. Actuators, B, 2017, 242, 1201-1209; (b) Y. Yang, J. Cheng, B. Wang, Y. Guo, X. Dong and J. Zhao, Microchim. Acta, 2019, 186, 101-111.

44 (a) X. Jiang, Z. Wang, H. Wang, Y. Zhuo, R. Yuan and Y. Chai, Chem. Commun., 2017, 53, 9705-9708; (b) Z.-H. Zhang, F.-H. Duan, J.-Y. Tian, J.-Y. He, L.-Y. Yang, H. Zhao, S. Zhang, C.-S. Liu, L.-H. He, M. Chen, D.-M. Chen and M. Du, ACS Sens., 2017, 2, 982-989; (c) F. Su, S. Zhang, H. Ji, H. Zhao, J.-Y. Tian, C.-S. Liu, Z. Zhang, S. Fang, X. Zhu and M. Du, ACS Sens., 2017, 2, 998-1005; (d) C.-S. Liu, C.-X. Sun, J.-Y. Tian, Z.-W. Wang, H.-F. Ji, Y.-P. Song, S. Zhang, Z.-H. Zhang, L.-H. He and M. Du, Biosens. Bioelectron., 2017, 91, 804-810; (e) C. Gu, C. Guo, Z. Li, M. Wang, N. Zhou, L. He, Z. Zhang and M. Du, Biosens. Bioelectron., 2019, 134, 8-15; $(f)$ M. Wang, M. Hu, Z. Li, L. He, Y. Song, Q. Jia, Z. Zhang and M. Du, Biosens. Bioelectron., 2019, 142, 111536.

45 T. Y. Huang, C. W. Kung, Y. T. Liao, S. Y. Kao, M. Cheng, T. H. Chang, J. Henzie, H. R. Alamri, Z. A. Alothman, Y. Yamauchi, K. C. Ho and K. C.-W. Wu, Adv. Sci., 2017, 4, 1700261.

46 W. Morris, B. Volosskiy, S. Demir, F. Gándara, P. L. McGrier, H. Furukawa, D. Cascio, J. F. Stoddart and O. M. Yaghi, Inorg. Chem., 2012, 51, 6443-6445.

47 M. Cao, X. Yin, X. Bo and L. Guo, J. Electroanal. Chem., 2018, 824, 153-160.

48 H. Wang, Q. Hu, Y. Meng, Z. Jin, Z. Fang, Q. Fu, W. Gao, L. Xu, Y. Song and F. Lu, J. Hazard. Mater., 2018, 353, 151157.

49 J. Gu, X. Yin, X. Bo and L. Guo, ChemElectroChem, 2018, 5, 2893-2901.

50 W. Zhang, L. Zong, G. Geng, Y. Li and Y. Zhang, Sens. Actuators, B, 2018, 257, 1099-1109.

51 L. Wang, T. Meng, Y. Fan, C. Chen, Z. Guo, H. Wang and Y. Zhang, J. Colloid Interface Sci., 2018, 524, 1-7.

52 K. S. Park, Z. Ni, A. P. Cote, J. Y. Choi, R. Huang, F. J. UribeRomo, H. K. Chae, M. O'Keeffe and O. M. Yaghi, Proc. Natl. Acad. Sci. U. S. A., 2006, 103, 10186-10191.

53 L. Chen, Y. Peng, H. Wang, Z. Gu and C. Duan, Chem. Commun., 2014, 50, 8651-8654.

54 J. Guan, Y. Hu, Y. Wang, H. Li, Z. Xu, T. Zhang, P. Wu, S. Zhang, G. Xiao, W. Ji, L. Li, M. Zhang, Y. Fan, L. Li, B. Zheng, W. Zhang, W. Huang and F. Huo, Adv. Mater., 2017, 29, 1606290.

55 T. Zhang, L. Wang, C. Gao, C. Zhao, Y. Wang and J. Wang, Nanotechnol., 2018, 29, 074003.

56 G. D. Tarlas, A. D. Katsenis and G. S. Papaefstathiou, Eur. J. Inorg. Chem., 2018, 4458-4464.

57 K. Liu, H. You, G. Jia, Y. Zheng, Y. Huang, Y. Song, M. Yang, L. Zhang and H. Zhang, Cryst.Growth Des., 2010, 10, 790-797.

58 J. Zhang, X. Xu and L. Chen, Sens. Actuators, B, 2018, 261, 425-433.

59 Z. Chang, N. Gao, Y. Li and X. He, Anal. Methods, 2012, 4, 4037-4041.
60 M. H. Alkordi, Y. Liu, R. W. Larsen, J. F. Eubank and M. Eddaoudi, J. Am. Chem. Soc., 2008, 130, 12639-12641.

61 Y. Liu, V. C. Kravtsov, R. Larsen and M. Eddaoudi, Chem. Commun., 2006, 14, 1488-1490.

62 Y. Wang, K. Du, Y. Chen, Y. Li and X. He, Anal. Methods, 2016, 8, 3263-3269.

63 D. Y. Hong, Y. K. Hwang, C. Serre, G. Ferey and J. S. Chang, Adv. Funct. Mater., 2009, 19, 1537-1552.

64 Y. K. Seo, J. W. Yoon, J. S. Lee, J. K. Hwang, C. H. Jun, J. S. Chang, S. Wuttke, P. Bazin, A. Vimont, M. Daturi, S. Bourrelly, P. L. Llewellyn, P. Horcajada, C. Serre and G. Ferey, Adv. Mater., 2012, 24, 806-810.

65 H. Guo, Z. Zheng, Y. Zhang, H. Lin and Q. Xu, Sens. Actuators, B, 2017, 248, 430-436.

66 M. Roushani, A. Valipour and Z. Saedi, Sens. Actuators, B, 2016, 233, 419-425.

67 Y. Wang, L. Wang, W. Huang, T. Zhang, X. Hu, J. A. Perman and S. Ma, J. Mater. Chem. A, 2017, 5, 8385-8393.

68 M. Chen, N. Gan, Y. Zhou, T. Li, Q. Xu, Y. Cao and Y. Chen, Sens. Actuators, B, 2017, 242, 1201-1209.

69 X. Zhao, W. Bai, Y. Yan, Y. Wang and J. Zhang, J. Electrochem. Soc., 2019, 166, B873-B880.

70 J. C. Jin, J. Wu, G. P. Yang, Y. L. Wu and Y. Y. Wang, Chem. Commun., 2016, 52, 8475-8478.

71 S. D. Richardson, Anal. Chem., 2011, 84, 747-778.

72 (a) S. N. Kim, J. Kim, H. Y. Kim, H. Y. Cho and W. S. Ahn, Catal. Today, 2013, 204, 85-93; (b) F. Jeremias, V. Lozan, S. K. Henninger and C. Janiak, Dalton Trans., 2013, 42, 15967-15973; (c) S. Vaesen, V. Guillerm, Q. Y. Yang, A. D. Wiersum, B. Marszalek, B. Gil, A. Vimont, M. Daturi, T. Devic, P. L. Llewellyn, C. Serre, G. Maurin and G. De Weireld, Chem. Commun., 2013, 49, 10082-10084; (d) Q. Xu, Y. Wang, G. Jin, D. Jin, K. Li, A. Mao and X. Hu, Sens. Actuators, B, 2014, 201, 274-280.

73 R. Witholt, R. H. Gwiazda and D. R. Smith, Neurotoxicol. Teratol., 2000, 22, 851-861.

74 M. Lu, Y. Deng, Y. Luo, J. Lv, T. Li, J. Xu, S. W. Chen and J. Wang, Anal. Chem., 2018, 91, 888-895.

75 (a) B. Cheng, L. Zhou, L. Lu, J. Liu, X. Dong, F. Xi and P. Chen, Sens. Actuators, B, 2018, 259, 364-371; (b) A. A. Ensafi, P. Nasr-Esfahani and B. Rezaei, Sens. Actuators, B, 2018, 270, 192-199.

76 Z. Guo, D. D. Li, X. K. Luo, Y. H. Li, Q. N. Zhao, M. M. Li, Y. T. Zhao, T. S. Sun and C. J. Ma, J. Colloid Interface Sci., 2017, 490, 11-22.

77 Y. Wei, C. Gao, F. L. Meng, H. H. Li, L. Wang, J. H. Liu and X. J. Huang, J. Phys. Chem. C, 2012, 116, 1034-1041.

78 (a) A. Pournara, A. Margariti, G. D. Tarlas, A. Kourtellaris, V. Petkov, C. Kokkinos, A. Economou, G. S. Papaefstathiou and M. J. Manos, J. Mater. Chem. A, 2019, 7, 15432-15443; (b) A. Margariti, S. Rapti, A. D. Katsenis, T. Friščić, Y. Georgiou, M. J. Manos and G. S. Papaefstathiou, Inorg. Chem. Front., 2017, 4, 773-781.

79 (a) L. Xiao, H. Xu, S. Zhou, T. Song, H. Wang, S. Li, W. Gan and Q. Yuan, Electrochim. Acta, 2014, 143, 143-151; (b) N. Serrano, J. M. Díaz-Cruz, C. Ariño and M. Esteban, 
Anal. Bioanal. Chem., 2009, 396, 1365-1369; (c) P. S. Adarakatti, V. Gangaiah and A. Siddaramanna, Mater. Sci. Semicond. Process., 2018, 84, 157-166.

80 (a) C. Mousty, Appl. Clay Sci., 2004, 27, 159-177;

(b) D. R. Rolison, Chem. Rev., 1990, 90, 867-878;

(c) B. J. Sanghavi, P. K. Kalambate, S. P. Karna and A. K. Srivastava, Talanta, 2014, 120, 1-9; (d) K. Kalcher, Electroanalysis, 1990, 2, 419-433.

81 (a) S. Alwarappan, G. Liu and C.-Z. Li, Nanomedicine, 2010, 6, 52-57; (b) D. P. Quan, D. P. Tuyen, T. D. Lam, P. T. N. Tram, N. H. Binh and P. H. Viet, Colloids Surf., B, 2011, 88, 764-770; (c) C.-L. Sun, C.-T. Chang, H.-H. Lee, J. Zhou, J. Wang, T.-K. Sham and W. F. Pong, ACS Nano, 2011, 5, 7788-7795; (d) D. Jia, J. Dai, H. Yuan, L. Lei and D. Xiao, Talanta, 2011, 85, 2344-2351; (e) X. Liu, Y. Peng, X. Qu, S. Ai, R. Han and X. Zhu, J. Electroanal. Chem., 2011, 654, 72-78; (f) S. He, Y. Yu, Z. Chen, Q. Shi and L. Zhang, Anal. Lett., 2014, 48, 248-258.

82 (a) C. F. Tang, S. A. Kumar and S. M. Chen, Anal. Biochem., 2008, 380, 174-183; (b) J. Huang, Y. Liu, H. Hou and T. You, Biosens. Bioelectron., 2008, 24, 632-637; (c) M. S. Hsu, Y. L. Chen, C. Y. Lee and H. T. Chiu, ACS Appl. Mater. Interfaces, 2012, 4, 5570-5575; (d) J. Du, R. Yue, F. Ren, Z. Yao, F. Jiang, P. Yang and Y. Du, Gold Bull., 2013,
46, 137-144; (e) C. L. Sun, H. H. Lee, J. M. Yang and C. C. Wu, Biosens. Bioelectron., 2011, 26, 3450-3455; (f) M. Hadi and A. Rouhollahi, Anal. Chim. Acta, 2012, 721, 55-60; $(g)$ S. Palanisamy, Mater. Res. Express, 2014, 1, 045020 .

83 (a) H. Filik, A. A. Avan, S. Aydar and R. B. Arpac1, Int. J. Electrochem. Sci., 2014, 9, 2775-2789; (b) D. Han, T. Han, C. Shan, A. Ivaska and L. Niu, Electroanalysis, 2010, 22, 2001-2008; (c) X. Liu, X. Ou, Q. Lu, J. Zhang, S. Chen and S. Wei, RSC Adv., 2014, 4, 42632-42637; (d) Y. Wang and C. Bi, J. Mol. Liq., 2013, 177, 26-31; (e) C. Wang, R. Yuan, Y. Chai, Y. Zhang, F. Hu and M. Zhang, Biosens. Bioelectron., 2011, 30, 315-319.

84 (a) S. Rapti, D. Sarma, S. A. Diamantis, E. Skliri, G. S. Armatas, A. C. Tsipis, Y. S. Hassan, M. Alkordi, C. D. Malliakas, M. G. Kanatzidis, T. Lazarides, J. C. Plakatouras and M. J. Manos, J. Mater. Chem. A, 2017, 5, 14707-14719; (b) S. Rapti, S. A. Diamantis, A. Dafnomili, A. Pournara, E. Skliri, G. S. Armatas, A. C. Tsipis, I. Spanopoulos, C. D. Malliakas, M. G. Kanatzidis, J. C. Plakatouras, F. Noli, T. Lazarides and M. J. Manos, J. Mater. Chem. A, 2018, 6, 20813-20821; (c) P. Kumar, A. Pournara, K. H. Kim, V. Bansal, S. Rapti and M. J. Manos, Prog. Mater. Sci., 2017, 86, 25-74. 